\title{
Separation technology-Making a difference in biorefineries
}

DOI:

10.1016/j.biombioe.2016.05.021

\section{Document Version}

Accepted author manuscript

Link to publication record in Manchester Research Explorer

\section{Citation for published version (APA):}

Kiss, A. A., Lange, J. P., Schuur, B., Brilman, D. W. F., van der Ham, A. G. J., \& Kersten, S. R. A. (2016).

Separation technology-Making a difference in biorefineries. Biomass and Bioenergy, 95, 296-309.

https://doi.org/10.1016/j.biombioe.2016.05.021

\section{Published in:}

Biomass and Bioenergy

\section{Citing this paper}

Please note that where the full-text provided on Manchester Research Explorer is the Author Accepted Manuscript or Proof version this may differ from the final Published version. If citing, it is advised that you check and use the publisher's definitive version.

\section{General rights}

Copyright and moral rights for the publications made accessible in the Research Explorer are retained by the authors and/or other copyright owners and it is a condition of accessing publications that users recognise and abide by the legal requirements associated with these rights.

\section{Takedown policy}

If you believe that this document breaches copyright please refer to the University of Manchester's Takedown Procedures [http://man.ac.uk/04Y6Bo] or contact uml.scholarlycommunications@manchester.ac.uk providing relevant details, so we can investigate your claim.

\section{OPEN ACCESS}




\title{
Separation technology - Making a difference in biorefineries
}

\author{
Anton A. Kiss, ${ }^{1,2 *}$ Jean-Paul Lange, ${ }^{1,3}$ Boelo Schuur, ${ }^{1}$ \\ D. W. F. Brilman, ${ }^{1}$ A. G. J. van der Ham, ${ }^{1}$ Sascha R. A. Kersten ${ }^{1}$ \\ ${ }^{1}$ Sustainable Process Technology Group, Faculty of Science and Technology, University of \\ Twente, PO Box 217, 7500 AE Enschede, The Netherlands \\ ${ }^{2}$ AkzoNobel Research, Development \& Innovation, Process Technology SRG, Zutphenseweg \\ 10, 7418 AJ Deventer, The Netherlands \\ ${ }^{3}$ Shell Global Solutions International B.V., Shell Technology Centre Amsterdam, Grasweg \\ 31, $1031 \mathrm{HW}$, Amsterdam, The Netherlands
}

Keywords: Separation technology, Biomass conversion, Process intensification, Biorefinery

\section{Highlights}

- Separation and purification accountable for largest part of costs in biorefineries

- Hybrid technologies based on process intensification ready to make a big difference

- Energy efficient separation technologies that require low CapEx and OpEx

\begin{abstract}
In the quest for a sustainable bio-based economy, biorefineries play a central role as they involve the sustainable processing of biomass into marketable products and energy. This paper aims to provide a perspective on applications of separations that can make a great difference in biorefineries, by significantly reducing the costs and thus making the processes competitive without subsidies. A parallel is drawn between bio-refinery and petro-refinery, to highlight the specific separation challenges encountered in biorefineries and point out the impact of separations on the total costs. Existing and foreseen separations in biorefineries are reviewed, and the upcoming challenges in the bio-domain (additional to current fossil) are identified. Relevant industrial examples are provided to illustrate the tremendous ecoefficiency benefits of well-designed separation processes based on process intensification principles (e.g. reactive separations, dividing-wall column, affinity and trigger-enhanced separations). These examples also illustrate the low sustainability of several bio-separations currently practiced, in terms of high relative energy requirements, large amounts of gypsum co-production and/or excess use of caustic.
\end{abstract}

\footnotetext{
*Corresponding author: TonyKiss@gmail.com, Tel: +31 263669420
} 


\section{Introduction}

2 Biomass is nature's way of storing solar energy and is considered a renewable alternative to fossil resources. Biorefineries involve the sustainable processing of bioresources into a spectrum of marketable products and energy (IEA Bioenergy Task 42). However, this is not an entirely new concept, as biomass converting technologies (sugar, starch, pulp \& paper) have been around for a long time and these can be partly considered as biorefineries. As the biorefinery concept evolved, a variety of criteria is used now for the taxonomy: technological implementation status, type of raw material used, main intermediate produced, conversion process applied, or a combination of these features (de Jong and Jungmeier, 2015). Remarkably, the nature is fully able to operate efficiently with a mix of reactants that lead to a mix of products. Hence Mother Nature does not offer pure chemicals to the humankind. The chemical industry, on the other hand, developed along the line of using almost pure raw materials (obtained in pre-treatment steps) that are converted into a mix of products which are separated afterwards into pure components/intermediates. These are then combined to make materials with well-tuned and controlled structures and properties. Thus, purity is (so far) the key to control these processes.

A comparison between the oil refineries and biorefineries will help to put things into context and show the role of separation technology in both cases. Figure 1 illustrates this analogy. A classical refinery transforms fossil sources (oil \& gas) into energy, fuels, and chemicals. The raw materials are converted first into building blocks, from which more valuable intermediates and end-user products are obtained. The separation and purification steps in oil refineries typically use distillation technologies (along with liquid extraction, crystallization, absorption, adsorption, membranes) that can account for $40-50 \%$ of the total costs (Kiss, 2013). A biorefinery has quite similar functions to a classic refinery, but in this case the feedstock used is biomass instead of oil. In addition to the production of energy, fuels and chemicals, a biorefinery may also produce bioproducts such as food for humans and livestock. On the way to chemicals, the biomass is converted to biochemical building blocks, a set of functional molecules that are more suitable for organic synthesis. It is worth noting that all separation technologies applied in biorefineries are derivatives from the petro-chemical industry. As the balance in properties of the streams is different than the ones in petrochemical industry, a different balance/emphasis in separation technologies could be expected. The biomass pre-treatment step (involving mainly phase separations, but also size reduction, removing dirt/sand, etc.) already leads to some primary products, and it is responsible for 20$40 \%$ of the total costs (Ramaswamy et al., 2013). Afterwards the conditioned biomass is used 
1 on dedicated technology platforms where it is converted into products. These platforms are 2 primarily determined by the chemistry routes and the feedstock composition (de Jong et al., 2012). Several technology platforms are available, such as: biogas (methane from anaerobic digestion), syngas (a mixture of $\mathrm{CO}$ and $\mathrm{H}_{2}$ from gasification for Fischer-Tropsh synthesis), hydrogen (by steam reforming, water electrolysis, or fermentation), C6 sugars (hydrolysis of sucrose, starch, cellulose and hemicellulose), C5 sugars (hydrolysis of hemicellulose), lignin (from lignocellulosic biomass processing), pyrolysis oil or bio-crude (hydrothermal liquefaction oil, as obtained by a thermo-chemical biomass-to-liquid technology), oils and fats (from oil crops, algae and waste oils), organic juice (liquid after pressing wet biomass), electricity and heat (internal use or to grid). These platforms produce in most cases liquid or gas mixtures of components that require expensive separation steps contributing to the largest part of the total costs (Ramaswamy et al., 2013; de Jong and Jungmeier, 2015).

While there are many recent books and reviews tackling the topic of biorefinery - mainly the pre-treatment and conversion steps (Centi and van Santen, 2007; Kamm et al., 2010; FitzPatrick et al., 2010; Cherubini, 2010; Naik et al., 2010; Pandey and Kim, 2011; Bridgwater 2012; Aresta et al., 2012; Stuart and El-Halwagi, 2012; Pandey et al., 2015; and others) - there are only very few publications dedicated to the (role of) separation technology in biorefineries (Huang et al., 2008; Ramaswamy et al., 2013). These latter papers give an overview of available separation technologies and discuss some applications, but no critical evaluation is made and no boundary conditions are provided for the actual applicability.

This perspective paper aims to fill this gap, by identifying the key challenges (caused by reactivity, polarity, dilution, complex matrix) and foreseen separations in the envisaged biorefineries, raising some warning signals with regard to several unsustainable separations that should be avoided, while indicating when certain separations are applicable or not by using relevant examples. An overview is given with regard to applications of separation technologies that can make a great difference in biorefineries by simplifying processes (less equipment) and reducing the operating costs (lower energy requirements), making the biorefineries more competitive even without any subsidy. The focus of this work is on the efficient separation (meaning molecular separation, not phase separation) of fluid mixtures using various technologies (e.g. reactive separations, advanced distillation, affinity and trigger-enhanced separations, etc). Several showcases are presented to illustrate the impact of separation on eco-efficiency. 


\section{2. Challenges and opportunities for separations in biorefineries}

In addition to biomass conversion steps (including pre-treatment), separation and purification of biomass converted components into products is of utmost importance for biorefinery applications. Compared to conventional chemical processes, the separation in biorefineries may be severely hindered by factors, such as (in case of water-based biorefineries): low feed concentration, product inhibition issues, and/or low product yield leading to very diluted (aqueous) streams that resemble more waste water streams than typical chemical reactor effluents. Note that we assume mainly water-based biorefinery streams throughout this paper. However, we will occasionally consider other type of biorefinery stream where appropriate, e.g. streams that consist of pyrolysis or liquefaction oils and lipids.

Moreover, the presence of water and oxygenated compounds forming complex matrices and azeotropes constitutes an additional difficulty as compared to oil refineries. Another key aspect is the production of high-volume low-value biofuels and/or low-volume high-value chemicals. The economy of scale in the biorefinery domain is at a different level as compared to fossil based refineries, as the mass yield of product to feed is typically much worse (with very few exceptions) thus making the CapEx per kg product even more important. In many cases the separation part is the crucial factor determining the commercial success of biorefineries, as it accounts for the largest part of the total costs (Ramaswamy et al., 2013; Kiss et al., 2015).

To summarize, the challenges in separation technology for biorefineries relate to the presence of reactive mixtures, often temperature restricted to $150{ }^{\circ} \mathrm{C}$, polarity of components present in the mixture, often much diluted aqueous solutions, and a complex matrix of organics that often contains also inorganic compounds with a detrimental effect on extraction. Examples of separation challenges foreseen in the biorefineries include among others:

- Concentration of oxygenates from water (aqueous streams), as for example acids (e.g. acetic, lactic, succinic, levulinic) and/or their corresponding salts; light oxygenates (e.g. alcohols, carbonyls); heavy oxygenates (e.g. sugars)

- Removal of sugars from a mix of phenols (e.g. from pyrolysis oil)

- Separation of lights from heavies, with similar molecular structure (e.g. bio-oil)

- Decontamination of sugar (e.g. removal of furanics/phenolics for fermentation, and removal of amino acids/ash for chemo catalysis)

- Fractionating (algal/microbial) biomass in lipids, proteins, carbohydrate rich fractions With the risk of oversimplification, the novelty of many separation challenges relies on two 
1 main characteristics of the streams, namely their thermal instability and high dilution. These challenges are partly compensated by an important opportunity: bio-based components are generally highly polar and functional hence offer opportunities for intermolecular affinities. Thermal instability is a key issue in biorefineries since it hinders the workhorse of separation technologies, the classic distillation. Complex and reactive mixtures (prone to fouling) are obtained from processing of lignocellulose or sugar streams, and they contain hundreds of components as found in liquefaction and pyrolysis oil, or the sugar product stream from acid or hydrogenation/hydrogenolysis processes. The thermal instability results mainly from the presence high functionalized molecules, which contain reactive functionalities such as hydroxyls, aldehydes, ketones and carboxylic acid groups or furanic rings. The challenge is further worsened by the fact that biorefinery streams often consist of complex mixtures containing hundreds of components and often come at low pH (Lange, 2015). Dewatering the product may worsen the situation by increasing the concentration of reactive components and contained acids. This makes subsequent separation at high temperature (e.g. by distillation), unfavorable compared to alternative low-temperature separations (e.g. LLX, permeation). But a few alternative distillation technologies may still be worth considering, e.g. vacuum distillation, molecular distillation, short-path distillation, pass-through distillation. Such an example is the separation of phenolics from bio-oil (Elkasabi et al., 2014).

Diluted (aqueous) solutions require typically a pre-concentration before the actual separation and purification. Indeed biomass conversion often proceeds in diluted liquid phase e.g. as diluted sugar stream (e.g. sugar juice or starch/cellulose hydrolysate) or derivatives from such stream (e.g. after conversion of the diluted sugars to a variety of oxygenates such as alcohols, polyols, acids or furanics). High dilution often results in large reaction processing equipment and expensive separation schemes. The abundant solvent (generally water) is generally lighter than the desired product hence, re-concentration by solvent evaporation can be an expensive endeavor (due to the high enthalpy of vaporization of water). Alternative, non-distillative reconcentration may include precipitation (e.g. of acid salts), extraction (e.g. of furanics and phenolics) or ultrafiltration (e.g. of bio-oils and other high molecular weight products). Large feed variability is expected in the feed streams entering the separation or purification stages in a biorefinery compared to the low variability in a regular oil refinery. This is clearly the outcome of the large diversity in terms of properties and content that the raw biomass may possess. Such variability may greatly affect the performance of the separation and purification processes and would require a very careful design of the processes in order to achieve their 
1 targets. As variability may affect some process configurations more than other factors, with a

2 direct economic impact, this issue has to be considered in the separation process selection.

3 Feed detoxification is a peculiar case of separation with diluted feed. Microorganisms used

4 for sugar fermentation are often sensitive to low concentration of toxins such as acetate, furanic or phenolics. In contrast, chemical catalysts are more sensitive to either basic minerals (e.g. for acid-catalysis) and/or N-, S- and Cl-components (e.g. for hydrogenation) contained in the feed (Lange, 2015). New and inexpensive technologies for feed detoxification will likely become of prime importance. Owing to the low concentration of toxins, feed detoxification will likely include ion-exchange, adsorption, extraction or precipitation. These separation challenges are particularly encountered in the front end of the biorefineries. Once these intermediate streams are upgraded to well-defined and thermally stable platform molecules, conventional distillation may come back as very effective approach. This does not mean that separation research ends here as biorefineries offer a wealth of opportunities in advanced distillations, e.g. azeotropic, extractive or reactive distillations.

\section{Applications of separations in biorefineries}

This section gives an overview of the main applications of key separation technologies in biorefineries, conveniently grouped here according to the separation mechanism. Additional details about each of these technologies are provided in the books of Seader et al. (2011), de Haan and Bosch (2013), Kiss (2013) and in particular Ramaswamy et al. (2013) who puts them in the context of biorefineries.

\subsection{Phase-change separations}

Distillation processes are used in biorefineries for the separation and dehydration of alcohols (bioethanol and biobutanol), purification of biodiesel, isolation of volatile organic compounds (essential oils) and phytochemicals from biomass (extract), concentration of chemicals in pyrolysis oil and separation of various fractions (alcohols, aldehydes, ketones, acids, phenolics and sugars). A particular case is the steam distillation process that is used for the direct separation of the desirable components from solid (not liquid) biomass feedstock (Bergeron et al., 2012; Ramaswamy et al., 2013). Distillation is a prime candidate for purification of final low molecular weight products, but it is not convenient for high-boiling components, particularly when these are highly functionalized and thus temperature sensitive. Precipitation and crystallization applications to biorefineries include: ethanol precipitation 
1 spent liquors from pulp mills, precipitation by acidification using $\mathrm{CO}_{2}$ or sulfuric acid applied to extract lignin from kraft black liquor, separation of succinic acid from fermentation broth or proteins from aqueous solutions (Huang et al., 2008; Ramaswamy et al., 2013).

Filtration is an established solid-liquid separation technology (Sparks and Chase, 2015). As solid biomass is typically the starting feedstock in biorefineries, a number of solid-liquid separation tasks (including filtration) are involved, such as the separation of prehydrolyzate and post-distillation slurries. Hence the use of efficient and cost-effective filtration processes is important for improving the overall process performance (Ramaswamy et al., 2013).

\subsection{Affinity-based separations}

Liquid-liquid extraction (LLX) plays an important role in biorefineries, being used for separating biofuels (bioalcohols) and chemicals (carboxylic acids) from dilute mixtures (fermentation broths), extraction of acetic acid from biomass hydrolysates using mixed solvents, extraction of 5-hydroxymethylfurfural (HMF) from an aqueous reaction solution using methyl isobutyl ketone (MIBK) as solvent, removing inhibitors from biomass hydrolyzates and various impurities (soap, methanol, and glycerol) from biodiesel, extraction of chemicals (aqueous extractions, or extraction with hydrophobic-polar solvent and antisolvent) of fast pyrolysis bio-oils, and extraction of succinic, maleic, lactic, and itaconic acids with ionic liquids, or by reactive extraction using amines (Huang et al., 2008; Ramaswamy et al., 2013). The main advantage of using LLX is in the recovery of (diluted) components that are boiling at higher temperature than the solvent (water) and are thermo-sensitive. Extraction avoids or minimizes the need to distil out huge amounts of water, which is very energy intensive. Depending on concentration and nature of the solute, reactive extraction with e.g. amines could be required due to the low extractability with physical solvents such as MIBK. Relatively low boiling solutes (e.g. acetic acid) can be stripped readily from such composite solvents (amines diluted in MIBK, 1-octanol or other diluents). For higher boiling solutes (e.g. lactic acid), direct thermal regeneration is not feasible due to stability issues of both solvent and solute. In such cases, extraction - back-extraction is applied (Krzyzaniak et al., 2014), aiming at concentrating the solution to the max, prior to further thermal purification.

Supercritical fluid extraction (SFE) using $\mathrm{CO}_{2}$ is very suitable for extracting hydrophobic constituents from biomass, e.g. recovery of value added phytochemicals (pigments, phenolics, carotenoids) and lipids from microalgae (Huang and Ramaswamy, 2012). The advantages of SFE are speed (no surface tension, low viscosities, fast diffusivity) and selectivity (properties of a sc-fluid can be altered by varying pressure and temperature). But the requirements for 
1 high pressures increases the process costs compared to conventional LLX, so SFE process

2 should be used only where the advantages are major and offset the drawbacks. In many cases SFE is used with the intent to avoid water distillation. Notably, the evaporation of water costs in terms of thermal energy $2.26 \mathrm{MJ} \mathrm{kg}^{-1}$, while the $\mathrm{CO}_{2}$ re-compression to supercritical conditions requires electricity up to $0.54 \mathrm{MJ} \mathrm{kg}^{-1}$ (i.e. $\sim 1.3 \mathrm{MJ} \mathrm{kg}^{-1}$ equivalent thermal energy when considering electricity generation).

Solid-liquid extraction (SLE) technology includes classic solid-liquid extraction, ultrasoundand microwave-assisted extraction, as well as pressurized subcritical liquid extraction. Biomass contains value-added co-products such as bioactive compounds and phytochemicals (phenolics, terpenes, sterols, enzymes, polysaccharides, alkaloids, toxins, and pigments) that can be extracted using SLE prior to or during conversion (Huang and Ramaswamy, 2012).

Absorption is used for the removal of acid gases $\left(\mathrm{H}_{2} \mathrm{~S}\right.$ and $\left.\mathrm{CO}_{2}\right)$ from syngas prior to further conversion into methanol and diesel fuel, or $\mathrm{CO}_{2}$ capturing. A particular method is reactive absorption that combines the absorption of gases in liquid solutions with simultaneous chemical reactions. This method is used for gas treatment and purification, removal of harmful substances, and the production of various industrial chemicals (Yildirim et al., 2012). Adsorption can be used in biorefineries for the efficient removal of inhibitors from biomass hydrolysate, separation and purification of biofuels and chemicals (dehydration of bioalcohols with molecular sieve), removal of impurities (glycerol, methanol, free fatty acids, soap, catalyst, metals, water and glycerides) from the raw biodiesel using magnesium silicate (Magnesol®) or magnesium silicate and bentonite as adsorbent (Ramaswamy et al., 2013).

Simulated moving bed (SMB) is often used for separation processes by adsorption in the biodomain: e.g. purification of glycerol from biodiesel production (using the Ambersep BD50 resin, or gel-type acidic ion-exchange resin beads) where the raffinate stream contains salts and organic impurities including FFAs, purification of oligosaccharides (made up of xylose and arabinose units), isolation of lactic acid from acetic acid, separation of sugars (glucose and xylose) and EmimAc (IL) from the biomass hydrolyzate (Ramaswamy et al., 2013).

\subsection{Size/charge-based separations}

Ion exchange (IEX) can be used in biorefineries for the removal of inhibitors from biomass hydrolysate (acid, salts), purification of biodiesel to remove impurities (FFA, glycerol, methanol, and soap using IEX resin Lewatit ${ }^{\circledR}$ GF202), separation of carboxylic acids, purification of succinic acid (IEXs are used for simultaneous acidification and crystallization) 
1 and of xylose from biomass prehydrolyzates (Ramaswamy et al., 2013). Fortunately, IEX also 2 trap other organics by means of adsorption.

3 Membrane separations, such as microfiltration $(0.050-10 \mu \mathrm{m})$, ultrafiltration $(1-100 \mathrm{~nm})$, and nanofiltration $(<2 \mathrm{~nm})$ can be used in biorefineries for the separation of biofuels and chemicals, depending on the molecules to be separated: e.g. removal of inhibitors (acetic acid), algal biomass harvesting, separation of hemicelluloses from biomass hydrolyzates (or process water of pulp mills), lignin recovery from pulp mill waste liquors or biomass prehydrolysis liquor, biodiesel separation and purification (Atadashi et al., 2011), separation of liquid mixtures (carboxylic acids recovery from dilute solutions), gas separation and purification (He et al., 2012; Ramaswamy et al., 2013). Membrane pervaporation/pertraction is a particular case - a highly selective, economical, safe, and eco-friendly technology - being a promising method for liquid-liquid separations in biorefineries, with applications such as the removal of inhibitory products from fermentation broth (Huang et al. 2008).

Electrodialysis is used in biorefineries for the separation of organic acids or carboxylic acids (acetic acid, oxalic acid, citric acid, gluconic acid, and succinic acid) from their fermentation broths (Huang et al., 2007), recovery of basic components such as mono-ethanol amine (de Groot et al., 2011), bipolar membrane electrodialysis for the production of organic bases (de Groot et al., 2011) and of lactic acid by continuous fermentation with an integrated product recovery process (Strathmann, 2010), as well as recovery of gluconic, ascorbic and succinic acids from their sodium salts (Wang et al., 2011; Ramaswamy et al., 2013).

\subsection{Reactive separations}

Mostly applied to equilibrium reactions (to drive the reaction to complete conversions) and insitu product removal (where the products are removed to avoid the bio-/catalyst poisoning), reactive separation processes make use of process intensification principles to combine the reaction and separation step in single unit, thus leading to significant advantages in terms of eco-efficiency: high conversion/yield, enhanced selectivity, high productivity, improved energy efficiency, and less equipment (Schmidt-Traub and Gorak, 2010; Kiss, 2013).

Reactive distillation (RD) is applied in biorefineries to the production of succinate esters, fatty esters \& biodiesel (Kiss, 2014), upgrade of flash pyrolysis oil, esterification of succinic and acetic acid from fermentation of biomass carbohydrates (Orjuela et al., 2011), esterification of glycerol to produce triacetin (Ramaswamy et al., 2013).

Reaction-membrane separations include membrane (bio)reactors, bioreactor-membrane pervaporation/distillation. Membrane reactors can be used for biodiesel production (Kiss, 2014), 
1 while fermentation-membrane pervaporation systems are used in butanol production (in situ 2 product-recovery technology). For succinic acid production a fermentation-bipolar membrane 3 electrodialysis system can be used (Ramaswamy et al., 2013).

4 Extractive fermentation applications in biorefineries include for example the extraction of 5 butanol from the fermentation broth (Dhamole et al., 2012). Proposed configurations consist of fermentation integrated with in-situ product removal, as well as external product removal in an extraction column with a recycle of product-lean broth. Membrane-assisted solvent extraction can also be used for recovery and separation of organic acids, biofuels, and other chemicals (Ramaswamy et al., 2013).

\subsection{Technology selection}

Based on our (industrial) experience we can draw the following recommendation of selecting separation technologies and give the following initial rules of thumb.

$\rightarrow$ Distillation is a strong option under the following conditions:

$\circ$ The temperature of thermal degradation of all components largely needs to exceed the reachable boiling point for distillates (at atmospheric or vacuum conditions).

○ The difference in boiling point of products to separate needs to exceed $5{ }^{\circ} \mathrm{C}$.

$\circ$ The concentration of the distillate needs to exceed $10 \%$ wt of the feed stream.

$\rightarrow$ Affinity separation is usable as an economical separation or pre-concentration method under specific conditions:

- Product and medium need to show significant differences in chemical affinity on at least one specific scale, e.g. acidity/basicity, polarity, H-bonding, etc.

- Low concentration of solute can be affordable if the affinity gap is sufficiently large to be exploited in an economical way.

○ The extractant needs to provide a moderate level of bonding, i.e. not too weak to ensure efficient extraction but at the same time not too strong to allow efficient regeneration (Jongmans et al., 2012).

○ Interactions of impurities (trace compounds) in the feed and the extractant need to be minimized.

- Very critical is an affordable sorbent recovery concept. This can be distillation (for extraction), thermal desorption (for adsorption), depressurization (for adsorption), or back extraction with a medium that is convenient for downstream processing. 
$\rightarrow$ Permeation is a viable option for separation when the right materials are available

- The product and medium need to show large difference in diffusivity. This is often related to molecular weight. However it can also imply difference in chemical affinity, when the diffusion proceeds via selective 'dissolution' in polymeric membrane, or in charge, i.e. in size of the solvated ion.

- The permeable materials should be able to cope with the large feed variability.

- The availability of affordable permeable materials (able to operate at extreme conditions) is critical to such processes and must be evaluated at early stages.

\section{Evaluation of separation processes}

Among others, process systems engineering (PSE) can contribute with shortcut methods that allow the techno-economic evaluations of separation processes. This section briefly provides some short cut methods to evaluate the cost of distillation and sustainability of separations. It is worth mentioning that mainly distillation and extraction, as well as micro/ultra/nanofiltration are used on large scale production in biorefineries, while other separation methods are still in research and development stage. However, in case of extraction the costs of recovery (often by distillation) determine the overall costs, while the cost of filtration largely depends on the cost of membranes (i.e. designated membrane area and type of material).

\subsection{Evaluation of distillation processes}

The cost of process segments, including complex distillation trains, was reported to be largely dictated by the duty of their major equipment (Lange et al., 1996, Lange, 2001). Indeed, the investment cost (inside battery limit) of process segments of fuel and chemical plants was shown to correlate with their overall energy transfer duty according to the following equation (cost updated to 2014):

Investment cost $\left(\right.$ ISBL, \$M 2014) $=4.7 *(\text { exchange duty }[\mathrm{MW}])^{0.55}$

Process flow modeling programs, which are now common tools for engineers, easily provide the equipment duties required by this equation. However, a well-converged and optimized process flow model may already be too demanding for a preliminary cost estimate. Simpler though cruder estimates may then become handy. A few decades ago, Rudd et al. (1973) eluded on such crude estimate by proposing to use the ratio 'feed flow / boiling-point difference' as indicator for distillation cost, e.g. for selecting the cheapest sequence of distillation columns for complex systems. However, they did not provide the support for this indicator, or any specific factor for converting this ratio into distillation cost. Building on this 
1 concept, the new concept of distillation resistance $\left(\mathrm{R}_{\mathrm{d}}\right)$ - detailed in another dedicated paper 2 (Lange, 2016) - can be taken as good proxy for the overall duty of a complex distillation and the overall distillation costs. This concept assumes that the thermal duty is determined by the fraction of the top streams (which are vaporized and then condensed), and the difference in boiling points of components to separate (which determine the reflux ratios). $R_{d}$ is defined as the sum of the individual ratio $\left(\mathrm{F}_{\mathrm{i}} / \Delta \mathrm{T}_{\mathrm{i}}\right)$ of all condensable distillates, where $\mathrm{F}_{\mathrm{i}}$ is the mass fraction [\%wt on total feed intake] of each component and $\Delta \mathrm{T}_{\mathrm{i}}$ is the temperature difference $\left[{ }^{\circ} \mathrm{C}\right]$ between its boiling point and that of the first heavier component in the feed.

$\mathrm{R}_{\mathrm{d}}\left[100 /{ }^{\circ} \mathrm{C}\right]=\sum \mathrm{F}_{\mathrm{i}}[\% \mathrm{wt}] / \Delta \mathrm{T}_{\mathrm{i}}\left[{ }^{\circ} \mathrm{C}\right]$

Simple distillations show $\mathrm{R}_{\mathrm{d}}<1$ and a duty of $\sim 1 \mathrm{GJ} \mathrm{t}^{-1}$ feed whereas demanding distillations show $\mathrm{R}_{\mathrm{d}}=3-7$ and a duty of 3-8 GJ $\mathrm{t}^{-1}$ feed. Reasonable linear regressions are proposed to relate $R_{d}$ with reboiler and total duties, which allow estimating the OpEx and overall CapEx.

Thermal duty $\left[\mathrm{GJ} \mathrm{t}^{-1}\right.$ feed] $=1.1 \times \mathrm{R}_{\mathrm{d}}$

Firing duty $\left[\mathrm{GJ} \mathrm{t}^{-1}\right.$ feed $]=0.6 \times \mathrm{R}_{\mathrm{d}}$

$$
\text { OpEx }\left[\$ \mathrm{t}^{-1} \text { feed }\right]=5\left[\$ \mathrm{GJ}^{-1}\right] * \text { Firing duty }\left[\mathrm{GJ} \mathrm{t} \mathrm{t}^{-1} \text { feed }\right]=3 \times \mathrm{R}_{\mathrm{d}}
$$

CapEx $\left[10^{6} \$, 2014\right]=4.7 *(\text { Thermal duty }[\mathrm{MW}])^{0.55}$

The concept of distillation resistance is based on an average distillation quality. Such assumption is reasonable when evaluating complex distillation trains that separate more than 5 streams. But care should be taken when stringent requirements are made on product purity or product recovery, particularly when the evaluation is limited to a single and demanding distillation. Also, when process intensification methods are employed (e.g. DWC technology) the capital and operating expenditures should be reduced by about 25\% (Kiss, 2013).

Besides the cost estimation of distillation, the energy efficiency of such processes can be also estimated. Pleşu et al. (2015) proposed a simple equation that is easily usable in calculations to evaluate the distillation sequence energy efficiency (DSE) for any alternative. DSE is calculated as the sum of feed molar fractions $\left(x_{\mathrm{i}}\right)$ multiplied by the product of column efficiencies - which are equal to the Carnot efficiency for distillates, $100 \%$ for bottoms product. In case of side stream products with boiling point higher than that of the feed, the efficiency is $100 \%$ - otherwise it corresponds to the Carnot efficiency of the column.

$D S E=\sum_{i=1}^{o}\left(x_{i} \prod_{C=1}^{N} \eta_{C}\right)($ maximize $)$

where $\eta_{\mathrm{C}}$ is the Carnot efficiency of the column: $\left.\eta_{\mathrm{C}}=\left(T_{\text {bottom }}-T_{\text {distillate }}\right) / T_{\text {bottom }}\right)$. Once DSE is calculated, all the alternative solutions can be sorted from higher to lower efficiency. 
1 Another simple criterion used especially when comparing various distillation alternatives with

2 each other is the $N_{S} \times(R R+1)$ which is directly proportional to the total annual costs (Kiss, 3 2013). This product includes the number of stages $\left(N_{\mathrm{S}}\right)$ that is proportional to the column 4 height $\mathrm{h}_{\mathrm{c}}$, and the reflux ratio + distillate $(R R+1)$ factor that is proportional to the column diameter $d_{c}$. Furthermore, $d_{c}$ is proportional to the production rate, while the reflux ratio + distillate $(R R+1)$ multiplied with the distillate rate $(D)$ and the heat of vaporization $\left(\Delta \mathrm{H}^{\mathrm{vap}}\right)$ gives the energy requirements of the distillation column:

$8 \quad C_{\text {shell }}=f_{p}(M \& S / 280) d_{c}{ }^{1.066} h_{c}{ }^{0.802}$

$\mathrm{C}_{\text {hex (reboiler/condenser) }}=(\mathrm{M} \& \mathrm{~S} / 280) \mathrm{c}_{\mathrm{x}} \mathrm{A}^{0.65}$

$\mathrm{C}_{\text {energy }}=(R R+1) D \Delta \mathrm{H}^{\mathrm{vap}}$ hours/year

where $f_{p}$ and $c_{x}$ are cost factors, $M \& S$ is the Marshall $\&$ Swift equipment cost index, $A$ is the heat exchange area. Note that in contrast to the previous methods, such analysis requires a short-cut or detailed modeling of the column, but is presumably more accurate.

\subsection{Evaluation of alternative separation processes}

The correlation between energy exchange duty and CapEx discussed above is not limited to distillation but can be extended to other separation technologies that are energy intensive, i.e. that require more than $10 \mathrm{MW}$ energy exchange. Large-scale extraction likely meets these requirements when the solvent is regenerated by means of distillation. Indeed, the solvent distillation column is likely to dominate the cost of the whole extraction train. The cost contribution of the extraction may then be accounted for by addition of a modest cost penalty of up to $25 \%$. By extension, the concept of distillation resistance $\mathrm{R}_{\mathrm{d}}$ may also be of value for a first estimate of CapEx. However, the accuracy might become questionable as only two components are separated.

In cases of separation train based on extraction and back extraction, the correlation between exchange duty and CapEx might not apply. The same is expected for other, more energy-lean separation technologies e.g. based on crystallization, precipitation, membrane permeation or ion-exchange. Other indicators need to be developed for such applications. One alternative indicator could be the mass transfer flux involved in the separation. This approach was proposed for evaluating the recovery of butanol, lactic acid and phenol from fermentation broth by means of adsorption, pervaporation, extraction and pertraction (Oudshoorn et al., 2010). The mass transfer flux was used to estimate the interfacial area and the vessel volume required for separation. Various equations are then used to derive CapEx and OpEx from the estimated separation volume. When applicable, the regeneration of the auxiliary phase was 
1 accounted for by doubling the CapEx and OpEx, with the assumption that regeneration follows the same limitations (e.g. same time constant) as the separation itself.

In case of membrane filtration, Pilutti and Nemeth (2003) reported capital costs of membrane systems starting at 198-462 $\$ \mathrm{~m}^{-3}\left(0.75-1.75 \$ \mathrm{gal}^{-1}\right)$ for a permeate capacity of $157-315 \mathrm{~m}^{3} \mathrm{~h}^{-1}$ (1-2 MGD, million gallons per day), but dropping fast to about $105 \$ \mathrm{~m}^{-3}\left(0.4 \$ \mathrm{gal}^{-1}\right)$ at 788 $\mathrm{m}^{3} \mathrm{~h}^{-1}(5 \mathrm{MGD})$ and even 53-106 $\$ \mathrm{~m}^{-3}\left(0.2-0.4 \$ \mathrm{gal}^{-1}\right)$ at capacities of $1577-6309 \mathrm{~m}^{3} \mathrm{~h}^{-1}(10-$ 40 MGD). The capital costs include membranes, skids, racks, compressors, blowers, pumps, piping, instrumentation, controls, and other components needed for a complete and operable system. However, the operating costs are more difficult to estimate as they depend on many factors including water quality, flux, recovery, pretreatment, and cost of consumables.

In a more recent study, Movahed (2010) estimated MF/UF capital costs in the range of 160$320 \$$ per $^{3}$ day $^{-1}$ (0.6-1.2 \$ per GPD) permeate capacity, and operating \& maintenance costs $(\mathrm{O} \& \mathrm{M})$ costs of $0.08-0.1 \$ \mathrm{~m}^{-3}\left(0.3-0.4 \$ \mathrm{Kgal}^{-1}\right)$ with overall water costs of $0.1-0.16 \$ \mathrm{~m}^{-3}$ (0.4-0.6 \$ $\left.\mathrm{Kgal}^{-1}\right)$. These costs include equipment, piping, controls, membrane replacement, chemicals and power but do not include building, site work, and finished water pumping.

\subsection{Critical evaluation of sustainability}

Sustainability of processes can be evaluated based on various metrics, such as the life-cycle analysis (LCA), eco-cost value (EVR) ratio, (socio-)eco-efficiency analysis, or the AIChE sustainability index (Dimian et al., 2014). It should be realized here that all separation must be economically and environmentally sensible. For instance, one needs to ensure that the value of the targeted product exceeds the recovery cost. This may imply that the energy required for recovering and purifying a bio-fuel component needs to remain a modest fraction of the heating value of the product itself.

One specific example of a bio-fuel is n-butanol, a fuel with an energy content of $36 \mathrm{MJ} \mathrm{kg}^{-1}$. Garcia-Chavez et al. (2012) calculated that a traditional thermal separation (two-distillation columns with a decanter after the first column to pass the heterogeneous azeotrope) uses about $21.3 \mathrm{MJ} \mathrm{kg}^{-1}$ to concentrate the n-butanol out of a $1 \mathrm{wt} \%$ solution, which is almost $60 \%$ of the energy content of butanol. In contrast, a process based on liquid extraction would only cost about $15 \%$ of the energy content, of which the majority was spent on evaporation of coextracted water. Even less energy consuming (3.76 $\mathrm{MJ} \mathrm{kg}^{-1}, 10.4 \%$ of the energy content of $\mathrm{n}$ butanol at a comparable feed concentration range of 0.4-1.2 wt $\%$ ) is the dual extraction process proposed by Kurkijärvi et al (2014), which benefits from one more hydrophilic solvent and one more hydrophobic solvent to reduce the losses of solvent to the raffinate and 
1 simultaneously reduces the heat required to evaporate co-extracted water. The efficiency of extraction processes is thus highly dependent on the selectivity of the solvent and the more selective, the less energy spent on evaporation of water. A similar conclusion can be drawn for a wider spectrum of separation technologies based on the overview papers of Oudshoorn et al. (2009) and Huang et al. (2014). Oudshoorn et al. (2009) considered a variety of technologies to recover n-butanol from fermentation broth and developed short-cuts for estimating their energy requirement. Not surprisingly, the separation selectivity appeared to largely dictate the energy efficiency of separation across all technologies. In fact, few technologies appeared to have an energy requirement that is lower than $\sim 10 \%$ of the heating value of n-butanol (36 $\mathrm{MJ} \mathrm{kg}^{-1}$ ). Figure 2 - based on the work of Oudshoorn et al. (2009) gives an overview of these technologies for butanol recovery.

Next to biofuels, also production of chemicals using fermentation is hindered by the typically low concentrations. To illustrate the effect of the concentration of the solute in the fermentation broth on energy demand of the recovery, Figure 3 plots the steam costs as function of the broth concentration when a traditional distillation would be used to separate the binary acetic acid / water mixture. When the steam cost is higher or equal to the product price then the process is obviously not economically feasible. A typical value aimed for is to have energy costs that are about or even less than $10 \%$ of the product price. It clearly follows that it is economically infeasible and unsustainable to recover acetic acid by distillation from the various fermentation processes, e.g. from a glucose fermentation to produce acetic acid in 5 wt $\%$ concentration, or from a fermented wastewater with only $1 \mathrm{wt} \%$. In traditional liquid extraction processes so called physical solvents are used, for example using ethyl acetate as in the text book example of Seader et al. (2011). With these solvents, distributions below unity are observed (IJmker et al. 2014), and the reduction in heat duty of approximately a factor of three is mainly due to the easier recovery by distillation than the initial process. For example, Seader et al. (2011) make advantageous use from a heterogeneous azeotrope. However, Figure 3 clearly shows that these physical solvents will not enable economic processes to recover acids from fermented wastewater, as the energy costs are higher than $10 \%$ of the product price. Chemically active solvents contain an extractant that complexes the acid, resulting in much higher distribution coefficients (Krzyzaniak et al., 2013; IJmker et al. 2014; Reyhanitash et al., 2015), but recovery of the acids from these complex-forming solvents is not as easy as from a physical solvent and typically involves a back-extraction after which further treatment is required. This is a nice example of the dilemma mentioned earlier of selecting an extractant that is neither too weak nor too strong. For the future developments in 
1 this field, there is a clear need for innovative process concepts, e.g. in the direction of $\mathrm{CO}_{2}-$ 2 enhanced extractions (Reyhanitash et al., 2015), that make a step reduction in the energy 3 demand such that the recovery costs become much lower than the product price.

4 New developments on the liquid-liquid extraction of organic acids are not only important for the reduction of the energy usage during the recovery of the solvent, but also with respect to the co-generation of large amounts of gypsum as byproduct from fermentation-based acid productions. In the traditional approach the fermentation is treated with $\mathrm{Ca}(\mathrm{OH})_{2}$ to maintain microbial activity also at higher acid concentrations, while the extraction is favored at low $\mathrm{pH}$. Hence the treatment with $\mathrm{H}_{2} \mathrm{SO}_{4}$ boosts the extraction efficiency, but co-generates large amounts of gypsum, e.g. for the industrial fermentative production of lactic acid this is about one ton of gypsum per ton of lactic acid, which is obviously unsustainable.

Although the focus in this section was limited to a single biofuel (n-butanol) and a single chemicals category (organic acids), the presented challenges in sustainable separations are certainly valid for a wide range of biorefineries, that typically deal with highly diluted streams and large amounts of water.

\section{Case studies of separations}

This section provides a selection of showcases, applicable to biofuels and chemicals, which illustrate the great impact of innovative separations in biorefineries.

\subsection{Advanced distillation}

Distillation remains a powerful separation technology, particularly at the high-value end of the biorefinery for the separation and purification of thermally stable and well defined components. New developments show much promises. Kiss (2013) illustrated the beneficial use of dividing-wall column (DWC) technology in the production of biofuels, leading to significant capital and energy savings. Of particular interest is bioethanol, a renewable fuel produced by various routes (corn-to-ethanol, sugarcane-to-ethanol, integrated lignocellulosic biomass-to-ethanol) in which the raw materials undergo several pre-treatment steps before entering the fermentation stage. All these technologies produce diluted bioethanol (typically $5-12 \%$ wt ethanol) that is further concentrated to reach the requirements of the international bioethanol standards. To reach the purity targets, an energy demanding separation is needed in practice, in order to overcome the presence of the binary azeotrope ethanol-water $(95.63 \% \mathrm{wt}$ ethanol). The separation is typically carried out by distillation, the first step being a preconcentration distillation column (PDC) that increases the ethanol content from 5-12\% up to 
1 91-94 \%wt. The second step consists of the ethanol dehydration, up to concentrations

exceeding the azeotropic composition. Quite a number of separation alternatives are available as described in the literature: pervaporation, adsorption, pressure-swing distillation, extractive distillation, azeotropic distillation, and hybrid methods combining these options (Vane, 2008). Among them, extractive distillation (ED) is still the option of choice in case of large scale production of bioethanol fuel. Typically, ED is performed in a sequence of two columns, one being the extractive distillation column (EDC) which separates ethanol, while the other one is the solvent recovery column (SRC) that recovers the mass separating agent that is recycled back in the process. Further improvements to the extractive distillation process were proposed, with the aim to increase the energy efficiency of bioethanol purification. One that stands out is a novel heat pump assisted extractive distillation process, based on mechanically driven heat pumps (Kiss and Infante Ferreira, 2016). This process efficiently combines vapor recompression (VRC) with dividing-wall column technology that allows the combination of all functions (three classic columns) into just one column - flowsheet shown in Figure 4 (Luo et al., 2015). Table 1 provides more details about the key performance indicators, including the total investment, operating and annual costs (Luo et al., 2015). Due to the use of a compressor and a larger side-reboiler required by the VRC system, the total investment cost of this VRC E-DWC process is about 29\% higher than for the classical process, but this is compensated by the significant energy savings, which exceed $60 \%$ at a direct comparison. The specific energy requirements are only $4.46 \mathrm{MJ} \mathrm{kg}^{-1}\left(1.24 \mathrm{kWh} \mathrm{kg}^{-1}\right)$ ethanol for the novel VRC assisted E-DWC, thus energy savings of over 50\% are possible as compared to other classic alternatives described in literature (Baeyens et al., 2015).

\subsection{Reactive separations}

Another opportunity of a bio-separation is reactive separation, being reactive distillation or reactive extraction, to circumvent difficulties in separation or in reaction (e.g. thermodynamic equilibrium or secondary product degradation).

Reactive distillation is an established technology, used for example in the recovery of acetic acid from aqueous liquors. Since acetic acid (normal boiling point of $118^{\circ} \mathrm{C}$ ) is higher boiling than water, recovering acetic acid by traditional distillation from dilute streams is not economical due to the large amount of water that needs to be removed overhead. One method relies on recovering the acetic acid in a valuable form, such as acetate. When a reactive distillation process is carried out, in which the acetic acid reacts with methanol, the formed methyl acetate (n.b.p. $57^{\circ} \mathrm{C}$ ) is then recovered and easily separated over the top (Agreda and 
1 Zoeller, 1993). More recently, Le et al. (2015) described a heterogeneous azeotropic 2 distillation schemes in a DWC for a feed mixture of water, acetic acid and an organic component (isobutyl acetate) that acts as an entrainer. Remarkable, the proposed Petlyuk DWC system proposed achieves energy savings of about $20 \%$.

Biodiesel production by reactive separations received significant attention during the past decade (Kiss, 2014). Being a mixture of fatty acid methyl esters (FAME), biodiesel is a renewable fuel used complementary to petro-diesel fuel. Its main synthesis routes are by either trans-esterification of tri-alkyl glycerides (TAG) or esterification of free fatty acids (FFA). Both routes use catalysts (homogeneous or solid acid / base catalysts) and can be applied in many types of industrial production processes (e.g. batch, continuous, supercritical, enzymatic, multi-step, reactive separations).

$\mathrm{TAG}+3 \mathrm{MeOH} \rightleftarrows 3 \mathrm{FAME}+$ Glycerol $\quad$ (trans-esterification)

$\mathrm{FFA}+\mathrm{MeOH} \rightleftarrows \mathrm{FAME}+\mathrm{H}_{2} \mathrm{O}$

(esterification)

The trans-esterification is mainly base catalyzed, while the esterification is catalyzed by acids - although alternative acid/base catalysts could be used but at prohibitive reaction rates. The reaction time can be dramatically shortened by increasing the liquid-liquid interfacial area by various process intensification techniques - e.g. static mixers, micro-channels reactors, microwaves assisted reactors, ultrasound assisted reactors, rotating / spinning tube reactors and centrifugal contactors (Qui et al., 2010) - or by integrating the reaction and separations steps to pull the equilibrium to full conversions, e.g. reactive distillation (Kiss and Bildea, 2012), reactive absorption, reactive extraction, reactive membrane separators (Kiss, 2014), and centrifugal contactors (Kraai et al., 2008). After the FAME synthesis stage, there are several down-stream processing steps required for catalyst neutralization and salt removal, alcohol recovery and recycle, as well as glycerol and biodiesel purification. Among the process intensification alternatives investigated, reactive distillation is the most promising option. Figure 5 illustrates a heat integrated reactive distillation process for fatty acids esterification, and a simpler one similar to reactive absorption (reactive column without reboiler and condenser). Table 2 provides the process parameters, whereas Figure 6 (Kiss and Bildea, 2012) compares the energy requirements for a classic two-step process based on pretreatment of free fatty acids and trans-esterification of glycerides versus reported reactive separation processes based on esterification of waste oils with high FFA content (Kiss, 2014). The figures are worth noting, especially considering the on-going quest on increasing the ecoefficiency of biodiesel production. The specific energy use in reactive separation processes is 
1 significantly lower than the FAME purification step alone in the conventional process. On top of the energy savings, the reactive separation processes benefit from lower investment costs and reduced plant footprint due to less equipment being used (Kiss and Bildea, 2012). Levulinic acid can be converted to nylon intermediates adipic acid or caprolactam. Key processing step include the hydrogenation to $\gamma$-valerolactone $(\mathrm{gVL})$, transesterification to alkyl pentenoate and e.g. methoxy carbonylation to methyl adipate. The transesterification can be performed under reactive distillation conditions. The concept was demonstrated to achieve $>95$ mol\% yield using various homogeneous and heterogeneous acids immersed in gVL with continuous feed of $\mathrm{MeOH}$ and stripping of Me-pentenoate entrained with $\mathrm{MeOH}$ vapor - as shown in Figure 7 (Lange et al., 2007).

Reactive distillation comes very handy for coupling levulinate ester with furfural to produce $\mathrm{C}_{10}$ oxygenates that can be subsequently converted to $\mathrm{C}_{10}$ hydrocarbons by hydrodeoxygenation (Lange et al., 2012). The coupling step is typically performed with an excess base (e.g. $\mathrm{NaHCO}_{3}$ ) and is followed by an acidification step to generate the acid form of the furfurylidene-levulinic acid intermediate. However, reactive distillation allows the use of a catalytic amount of base, e.g. solid base, by stripping water out of the medium and thereby avoiding hydrolysis of the ester and subsequent neutralization of the basic catalyst.

Reactive extraction is a very promising technology for the conversion of bio-based feedstock. Reactive extraction of cellulose-derived levulinic and formic acids with butene was proposed by Gürbüz et al. (2011) to obtain levulinate and formate esters, thereby allowing for recovery and recycle of sulfuric acid. The esters were converted over a dual-catalyst-bed system to GVL and 2-butanol, followed by production of butene to be recycled for reactive extraction and to be converted to liquid fuels by oligomerization. Another example of reactive extraction can be found in the conversion of sugars to furans. For instance, bi-phasic systems were explored for the conversion of fructose to HMF, as reviewed by Kuster (1990). Similarly, Moreau et al. (1998) converted xylose to furfural using HY and HMOR zeolites at $170^{\circ} \mathrm{C}$ using biphasic systems (water/toluene or the less effective water/MIBK). Beyond improved yield, biphasic operation also allows to recover the diluted furfural by solvent extraction rather than by distillation of the water-rich furfural/water azeotrope. Bi-phasic systems were further developed for both furfural and HMF by the group of Dumesic who proposed an integrated process based on sugar dehydration, furanics recovery and furanics upgrading (Roman-Leshkov et al., 2006). It is worth noting the recent identification of alkylphenols, which were reported to be effective extractant for furfural even 
1 at low extractant/water ratio and could be regenerated by simple distillation of furfural (Azadi et al., 2012). Such solvent could be produced from the lignin waste-product of the biorefinery.

\subsection{Triggered affinity separations}

The emphasis of this section is not so much on the extraction part that is typically the focus of most studies, but rather on the subsequent 'non-distillative' separation.

Extractions with operational swings. Following the reasoning above, the usefulness of thermal separations in biorefineries is limited to situations where reasonable concentrations of the desired products are obtained, e.g. bio-ethanol productions with yields of $5-12 \%$. For more diluted systems, it is generally better to apply affinity separation, such as (reactive) liquid-liquid extraction. Often, and especially when the distribution ratios - defined as

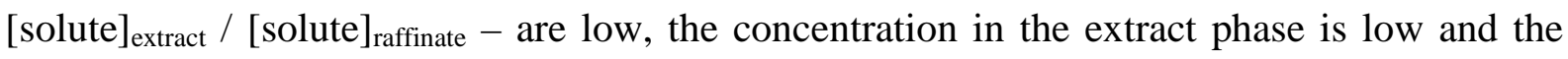
heat duty for direct thermal recovery from the solvent extremely high. Therefore, extraction back-extraction cycles are commonly used, in which achieving a high concentration factor is aimed for in order to facilitate further purification, e.g. by crystallization. The traditional approach to increase the ratio between the distribution ratio in the back-extraction stage and the distribution ratio in the extraction stage is to apply a temperature swing, but also diluent swings may be applied (Krzyzaniak et al., 2013). The drawback of applying a diluent swing is the need for an additional recovery step, in which the preferably low boiling diluent is evaporated before the solvent is sent back to the primary extraction process. More recently, the use of $\mathrm{CO}_{2}$ was reported to boost the distribution of acetic acid in an extraction from very dilute (1 wt\%) aqueous solutions resembling fermented aqueous wastewater (Reyhanitash et al., 2015). Using this approach, distribution ratios could be increased up to 7-fold, and the ratio of the acetic acid to co-extracted water increased from $1 \mathrm{wt} \%$ to $34 \mathrm{wt} \%$. In addition to the large concentration factor, a second benefit of using $\mathrm{CO}_{2}$ instead of a volatile organic diluent is that instead of a distillation, the added $\mathrm{CO}_{2}$ is simply removed from the system by depressurization which has a lower cost penalty than water evaporation. Extractions with temperature induced phase splitting. It is also possible to induce a phase split in a homogeneous system by applying a trigger. Temperature induced phase splitting is a concept that makes use of changes in miscibility with temperature. Due to a temperature change, the miscibility reduces, resulting in a phase split creating two liquid phases. Two temperature-dependent phase splitting events are known, one achieved when exceeding the lower critical solution temperature (LCST), and the other when cooling below the upper critical solution temperature (UCST). Both LCST-behavior and UCST behavior may be 
1 exploited in combination with liquid extraction. LCST behavior is mostly utilized in aqueous two-phase systems (ATPS) - see Figure 8 and Wohlfarth (2004) for more examples. ATPS systems have been applied for a range of applications interesting for biorefineries, e.g. for fractraction of salts (Milosevic et al., 2014), proteins (Grilo et al., 2016) and alkaloids (Freire et al. 2012). After the extraction, the solvent recovery is achieved by an induced phase split due to a mild temperature increase. Especially in biorefineries, the mildness of this technique valuable due to the sensitivity of many molecules (e.g. proteins), which in such ATPS may be isolated without losing their functionality. Examples of ATPS application include extraction of fatty acids (Glembin et al., 2014), and proteins (Desai et al., 2014) in algae biorefineries. Monteillet et al. (2014) showed another application of LCST behavior, where they combined LCST with a magnetoresponse to create multiresponsive ionic liquid emulsions capable of extracting $\beta$-carothene.

A very recent application of UCST behavior was recently reported by Kumar et al. (2015), who applied the induced phase splitting upon cooling in the fractionation of a complex bio-oil stream generated by thermal liquefaction of lignocellulosic biomass. This approach was then applied to recover the light fraction of the bio-oil for recycling as liquefaction medium - see Figure 9 (Kumar et al., 2015). This approach is based on hot extraction $\left(\mathrm{T} \sim 70{ }^{\circ} \mathrm{C}\right)$ of the light fraction of the oil with a suitable extraction solvent followed by cold $\left(\mathrm{T} \sim 25^{\circ} \mathrm{C}\right)$ de-mixing of the light fraction and the extraction solvent. The study illustrated the selection of the extraction solvent and definition of required solvent properties, showed the potential of multistage extraction / regeneration for the bio-oil produced by direct thermal liquefaction, extended the concept to fractionate a petroleum crude oil, discussed the theoretical basis of the fractionation using polymer solution theory, and showed a low energy requirement of the extraction process by means of process simulation, i.e., an equivalent of $\sim 1 \%$ of the biomass intake (Kumar et al., 2015).

Extractions with $\mathrm{CO}_{2}$-induced phase splitting. The concept of splitting phases by bubbling $\mathrm{CO}_{2}$ through a homogeneous system was first reported by Jessop et al (2005), and following this seminal paper, many publications appeared on extraction of lipids from natural sources such as soy bean (Phan et al., 2009) and microalgae (Boyd et al., 2012).

Du et al. (2013) have worked out a conceptual process scheme (Figure 10) for the extraction of lipids from microalgae using $\mathrm{CO}_{2}$ switchable secondary amines. It was shown that with the secondary amines it was actually possible to extract the lipids from wet algae. However, to make the benchmark hexane extraction efficient, drying of the algae prior to extraction was needed for good extraction efficiency. This type of process with its ability to extract from wet 
1 algae was further examined and compared with other technologies to extract lipids from algae

2 (Du et al., 2015). Although to date the research on this topic is ongoing, and detailed aspects of process elements like solvent recovery are still under investigation, the study showed that among the other technologies investigated (such as hexane extraction and extraction with supercritical $\mathrm{CO}_{2}$ ), using $\mathrm{CO}_{2}$-switchable solvents was the only approach to yield more energy (37.8 $\mathrm{MJ} \mathrm{kg}^{-1}$ lipids) than the separation costs (19.8 $\mathrm{MJ} \mathrm{kg}^{-1}$ lipids).

\section{Conclusions}

Separations in biorefineries are responsible for the largest part of the total costs and hence any major improvements in separations can make the difference between a commercial success and failure. By reviewing the existing and foreseen separations in biorefineries, identifying and discussing the additional challenges in the bio-domain, and providing an overview of applications of separation technologies in biorefineries, this perspective paper concludes that there are many opportunities to improve separations in biorefineries. A selection of relevant examples related to biofuels and chemicals proved that separation technology can make a big difference in biorefineries, by considerably reducing the overall energy requirements and the production costs, thus increasing competitiveness of bio-based fuels and chemicals.

\section{Acknowledgement}

The vivid and useful discussions with all the participants of the $1^{\text {st }}$ biorefinery conference (Biorefinery I: Chemicals and Materials from Thermo-Chemical Biomass Conversion and Related Processes, 27 Sep - 2 Oct 2015, Chania, Crete, Greece) are gratefully acknowledged.

\section{References}

1. Agreda V. H., Zoeller J. R., Acetic acid and its derivatives, Marcel Dekker, New-York, USA, 1993.

2. Aresta M., Dibenedetto A., Dumeignil F., Biorefinery: From biomass to chemicals and fuels, de Gruyter, Berlin, Germany, 2012.

3. Atadashi I., Aroua M. K., Aziz A. A., Biodiesel separation and purification: A review, Renewable Energy, 36 (2011), 437-443.

4. Azadi P., Carrasquillo-Flores R., Pagán-Torres Y. J., Gürbüz E. I., Farnood R., Dumesic J. A., Catalytic conversion of biomass using solvents derived from lignin, Green Chemistry, 14 (2012), 1573-1576.

5. Baeyens J., Kang Q., Appels L., Dewil R., Lv Y., Tan T., Challenges and opportunities in 
improving the production of bio-ethanol, Progress in Energy and Combustion Science, 47 (2015), 60-88.

6. Bergeron C., Carrier D. J., Ramaswamy S., Biorefinery co-products: Phytochemicals, primary metabolites and value-added biomass processing, John Wiley \& Sons, Chichester, UK, 2012.

7. Boyd A. R., Champagne P., McGinn P. J., MacDougall K. M., Melanson J. E., Jessop P. G., Switchable hydrophilicity solvents for lipid extraction from microalgae for biofuel production, Bioresource Technology, 118 (2012), 628-632.

8. Bridgwater A. V., Review of fast pyrolysis of biomass and product upgrading, Biomass and Bioenergy, 38 (2012), 68-94.

9. Centi G., van Santen R. A., Catalysis for renewables: From feedstock to energy production, Wiley-VCH, Weinheim, Germany, 2007.

10. Cherubini F., The biorefinery concept: Using biomass instead of oil for producing energy and chemicals, Energy Conversion and Management, 51 (2010), 1412-1421.

11. Christensen S. P., Donate F. A., Frank T. C., LaTulip R. J., Wilson L. C., Mutual solubility and lower critical solution temperature for water + glycol ether systems, Journal of Chemical Engineering Data, 50 (2005), 869-877.

12. de Groot M. T., Bos A. A. C. M., Lázaro A. P., de Rooij R. M., Bargeman G., Electrodialysis for the concentration of ethanolamine salts, Journal of Membrane Science, 371 (2011), 75-83.

13. de Groot M. T., de Rooij R. M., Bos A. A. C. M., Bargeman G., Bipolar membrane electrodialysis for the alkalinization of ethanolamine salts, Journal of Membrane Science, 378 (2011), 415-424.

14. de Haan A. B., H. Bosch, Industrial separation processes, De Gruyter, Berlin, Germany, 2013.

15. de Jong E., Higson A., Walsh P., Wellish M., Bio-based chemicals: Value-added products from biorefineries, International Energy Agency (IEA) report, Bioenergy Task 42, 2012.

16. de Jong E., Jungmeier G., Biorefinery concepts in comparison to petrochemical refineries, in Pandey A., Höfer R., Taherzadeh M., Nampoothiri M., Larroche C. (Eds), Industrial biorefineries \& white biotechnology, Elsevier, Waltham, USA, 2015.

17. Desai, R. K., Streefland, M., Wijffels, R. H., Eppink, M. H. M., Extraction and stability of selected proteins in ionic liquid based aqueous two phase systems, Green Chemistry, 16 (2014), 2670-2679.

18. Dhamole P. B., Wang Z., Liu Y., Wang B., Feng H., Extractive fermentation with non- 
ionic surfactants to enhance butanol production. Biomass and Bioenergy, 40 (2012), 112119.

19. Dimian A.C., Bildea C.S., Kiss A.A., Integrated design and simulation of chemical processes, 2nd edition, Elsevier, Amsterdam, The Netherlands, 2014.

20. Du Y., Schuur B., Samorì C., Tagliavini E., Brilman D. W. F., Secondary amines as switchable solvents for lipid extraction from non-broken microalgae, Bioresource Technology, 149 (2013), 253-260.

21. Du Y., Schuur B., Kersten S. R. A., Brilman D. W. F., Opportunities for switchable solvents for lipid extraction from wet algal biomass: An energy evaluation, Algal Research, 11 (2015), 271-283.

22. Elkasabi Y., Mullen C. A., Boateng A. A., Distillation and isolation of commodity chemicals from bio-oil made by tail-gas reactive pyrolysis, ACS Sustainable Chemistry \& Engineering, 2 (2014), 2042-2052.

23. FitzPatrick M., Champagne P., Cunningham M. F., Whitney R. A., A biorefinery processing perspective: Treatment of lignocellulosic materials for the production of valueadded products, Bioresource Technology, 101 (2010), 8915-8922.

24. Freire M. G., Cláudio A. F. M., Araújo J. M. M., Coutinho J. A. P., Marrucho I. M., Canongia Lopes J. N., Rebelo L. P. N., Aqueous biphasic systems: A boost brought about by using ionic liquids, Chemical Society Reviews, 41 (2012), 4966-4995.

25. Garcia-Chavez L. Y., Garsia C. M., Schuur B., de Haan A.B., Biobutanol recovery using nonfluorinated task-specific ionic liquids, Industrial \& Engineering Chemistry Research, 51 (2012), 8293-8301.

26. Glembin P., Racheva R., Kerner M., Smirnova I., Micelle mediated extraction of fatty acids from microalgae cultures: Implementation for outdoor cultivation, Separation and Purification Technology, 135 (2014), 127-134.

27. Grilo A. L., Aires-Barrosa M. R., Azevedo A. M., Partitioning in aqueous two-phase systems: Fundamentals, applications and trends, Separation \& Purification Reviews, 45 (2016), 68-80.

28. Gürbüz E. I., Alonso D. M., Bond J. Q., Dumesic J. A., Reactive extraction of levulinate esters and conversion to $\gamma$-valerolactone for production of liquid fuels, 4 (2011), 357-361.

29. He Y., Bagley D. M., Leung K. T., Liss S. N., Liao B.-Q., Recent advances in membrane technologies for biorefining and bioenergy production. Biotechnology Advances, 30 (2012), 817-858.

30. Huang C., Xu T., Zhang Y., Xue Y., Chen G., Application of electrodialysis to the 
production of organic acids: State-of-the-art and recent developments, Journal of Membrane Science, 288 (2007), 1-12.

31. Huang H. J., Ramaswamy S., Tschirner U. W., Ramarao B. V., A review of separation technologies in current and future biorefineries, Separation and Purification Technology 62 (2008), 1-21.

32. Huang H. J., Ramaswamy S., Separation and purification of phytochemicals as coproducts in biorefineries, 37-54, in Bergeron C., Carrier D. J., Ramaswamy S. (Eds), Biorefinery co-products: Phytochemicals, primary metabolites and value-added biomass processing, John Wiley \& Sons, Chichester, UK, 2012.

33. Huang H. J., Ramaswamy S., Liu Y., Separation and purification of biobutanol during bioconversion of biomass, Separation and Purification Technology, 132 (2014), 513-540.

34. IJmker H. M., Gramblicka M., Kersten S. R. A., van der Ham A. G. J., Schuur B., Acetic acid extraction from aqueous solutions using fatty acids, Separation and Purification Technology, 125 (2014), 256-263.

35. Jessop P. G., Heldebrant D. J., Li X., Eckert C. A., Liotta C. L., Green chemistry: Reversible nonpolar-to-polar solvent, Nature, 436 (2005), 1102-1102.

36. Jongmans M. T. G., Londono A., Mamilla S. B., Pragt H. J., Aaldering K. T. J., Bargeman G., Nieuwhof M. R., ten Kate A. J. B., Verwer P., Kiss A. A., van Strien C. J. G., Schuur B., de Haan A. B., Extractant screening for the separation of dichloroacetic acid from monochloroacetic acid by extractive distillation, Separation \& Purification Technology, 98 (2012), 290-297.

37. Kamm B., Gruber P. R., Kamm M., Biorefineries - Industrial processes and products: status quo and future directions, Wiley-VCH, Weinheim, Germany, 2010.

38. Kiss A. A., Novel applications of dividing-wall column technology to biofuel production processes, Journal of Chemical Technology and Biotechnology, 88 (2013), 1387-1404.

39. Kiss A.A., Advanced distillation technologies - Design, control and applications. Wiley, Chichester, UK, 2013.

40. Kiss A. A., Process intensification technologies for biodiesel production - Reactive separation processes, Springer, Heidelberg, Germany, 2014.

41. Kiss A. A., Bildea C. S., A review on biodiesel production by integrated reactive separation technologies, Journal of Chemical Technology and Biotechnology, 87 (2012), 861-879.

42. Kiss A. A., Grievink J., Rito-Palomares M., A systems engineering perspective on process integration in industrial biotechnology, Journal of Chemical Technology and Bio- 
technology, 90 (2015), 349-355.

43. Kiss A. A., Infante Ferreira C. A., Heat pumps in chemical process industry, CRC-Press (Taylor \& Francis Group), Boca Raton (FL), US, 2016.

44. Kurkijärvi A., Lehtonen J., Linnekoski J., Novel dual extraction process for acetonebutanol-ethanol fermentation, Separation and Purification Technology, 124 (2014), 18-25.

45. Kuster B. F. M., 5-Hydroxymethylfurfural (HMF) - A review focusing on its manufacture, Starch Starke, 42 (1990), 314-321.

46. Kraai G. N., van Zwol F., Schuur B., Heeres H. J., de Vries J. G., Two-phase (bio)catalytic reactions in a table-top centrifugal contact separator, Angewandte Chemie, 120 (2008), 3969-3972.

47. Kraai G. N., van Zwol F., Schuur B., Heeres H. J., de Vries J. G., Two-phase (bio)catalytic reactions in a table-top centrifugal contact separator. Angewandte Chemie International Edition, 47 (2008), 3905-3908.

48. Krzyżaniak A., Leeman M., Vossebeld F., Visser T. J., Schuur B., de Haan A. B., Novel extractants for the recovery of fermentation derived lactic acid, Separation and Purification Technology, 111 (2013), 82-89.

49. Krzyżaniak A., Schuur B., de Haan A. B., Equilibrium studies on lactic acid extraction with N,N-didodecylpyridin-4-amine (DDAP) extractant, Chemical Engineering Science, 109 (2014), 236-243.

50. Kumar S., Lange J-P., van Rossum G., Kersten S. R.A., Bio-oil fractionation by temperature-swing extraction: Principle and application, Biomass and Bioenergy, 83 (2015), 96-104.

51. Kumar S., Lange J-P., van Rossum G., Kersten S. R. A., Liquefaction of lignocellulose in fractionated light bio-oil: Proof of concept and techno-economic assessment, ACS Sustainable Chemistry \& Engineering, 3 (2015), 2271-2280.

52. Lange J-P., Fuels and chemicals manufacturing: Guidelines for understanding and minimising the production costs, CatTech, 5(2001), 82-95.

53. Lange J-P., Distillation in biorefineries - When is it affordable?, ACS Sustainable Chemistry \& Engineering (2016), Submitted for publication.

54. Lange J-P., Renewable feedstocks: The problem of catalyst deactivation and its mitigation, Angewandte Chemie International Edition, 54 (2015), 13186-13197.

55. Lange J-P., Tijm P. J. A., Processes for converting methane to liquid fuels: Economic screening through energy management, Chemical Engineering Science, 51 (1996), 23792387. 
56. Lange J-P., Vestering J. Z., Haan R. J., Towards 'bio-based' nylon: conversion of $\gamma$ valerolactone to methyl pentenoate under catalytic distillation conditions, Chemical Communications, 33 (2007), 3488-3490.

57. Lange J-P., van der Heide E., van Buijtenen J., Price R. J., Furfural - a promising platform for lignocellulosic biofuels, ChemSusChem, 5 (2012), 150-166.

58. Le Q-K., Halvorsen I. J., Pajalic O., Skogestad S., Dividing wall columns for heterogeneous azeotropic distillation, Chemical Engineering Research and Design, 99 (2015), 111-119.

59. Luo H., Bildea C. S., Kiss A. A., Novel heat-pump-assisted extractive distillation for bioethanol purification, Industrial \& Engineering Chemistry Research, 54 (2015), 22082213.

60. Milosevic M., Staal K. J. J., Bargeman G., Schuur B., de Haan A. B., Fractionation of aqueous sodium salts by liquid-liquid extraction in aqueous two phase systems, Separation and Purification Technology, 125 (2014), 208-215

61. Movahed B., Introduction and applications of low pressure membranes (MF/UF), AMTA Technology Transfer Workshop, Knoxville, Tennessee, May 4-6, 2010.

62. Monteillet H., Workamp M., Li X., Schuur B., Kleijn J. M., Leermakers F. A. M., Sprakel J., Multi-responsive ionic liquid emulsions stabilized by microgels, Chemical Communications, 50 (2014), 12197-12200.

63. Moreau C., Durand R., Peyron D., Duhamet J., Rivalier P., Selective preparation of furfural from xylose over microporous solid acid catalysts, Industrial Crops \& Products, 7 (1998), 95-99.

64. Naik S. N., Goud V. V., Rout P. K., Dalai A. K., Production of first and second generation biofuels: A comprehensive review, Renewable and Sustainable Energy Reviews, 14 (2010), 578-597.

65. Orjuela A., Kolah A., Lira C. T., Miller D. J., Mixed succinic acid / acetic acid esterification with ethanol by reactive distillation, Industrial and Engineering Chemistry Research, 50 (2011), 9209-9220.

66. Oudshoorn A., van der Wielen L. A. M., Straathof A. J. J., Assessment of options for selective 1-butanol recovery from aqueous solution, Industrial \& Engineering Chemistry Research, 48 (2009), 7325-7336.

67. Oudshoorn A., van den Berg C., Roelands C. P. M., Straathof A. J. J., van der Wielen L. A. M., Short-cut calculations for integrated product recovery options in fermentative production of bio-bulk chemicals, Process Biochemistry, 45 (2010), 1605-1615. 
68. Pandey M. P., Kim C. S., Lignin depolymerization and conversion: A review of thermochemical methods, Chemical Engineering \& Technology, 34 (2011), 29-41.

69. Pandey A., Höfer R., Taherzadeh M., Nampoothiri M., Larroche C., Industrial biorefineries \& white biotechnology, Elsevier, Waltham, USA, 2015.

70. Phan L., Brown H., White J., Hodgson A., Jessop P. G., Soybean oil extraction and separation using switchable or expanded solvents, Green Chemistry,11 (2009), 53-59.

71. Pilutti M., Nemeth J. E, Technical and cost review of commercially available MF/UF membrane products, International Desalination Association, 2003. (BAH03-029).

72. Pleşu V., Bonet Ruiz A. E., J. Bonet, Llorens J., Iancu P., Shortcut assessment of alternative distillation sequence schemes for process intensification, Computers \& Chemical Engineering, 83 (2015), 58-71.

73. Qiu Z. Y., Zhao L. N., Weather L., Process intensification technologies in continuous biodiesel production, Chemical Engineering and Processing, 49 (2010), 323-330.

74. Ramaswamy S., Huang H-J., Ramarao B. V., Separation and purification technologies in biorefineries, Wiley, Chichester, UK, 2013.

75. Reyhanitash E., Zaalberg B., IJmker H. M., Kersten S. R. A., B. Schuur, $\mathrm{CO}_{2}$-enhanced extraction of acetic acid from fermented wastewater, Green Chemistry, 17 (2015), 43934400.

76. Roman-Leshkov Y., Chheda J. N., Dumesic J. A., Phase modifiers promote efficient production of hydroxymethylfurfural from fructose, Science, 312 (2006), 1933-1937.

77. Rudd D. F., Powers G. J., Siirola J. J., Process synthesis, Prentice-Hall, Englewood Cliffs, USA, 1973.

78. Schmidt-Traub H., Gorak A., Integrated reaction and separation operations: Modelling and experimental validation, Springer, Berlin, Germany, 2010.

79. Seader J. D., Henley E. J., Roper D. K., Separation process principles, 3rd edition, Wiley, Hoboken NJ, 2011.

80. Sparks T., Chase G., Filters and filtration handbook, 6th edition, Butterworth-Heinemann, Oxford, UK, 2015.

81. Strathmann H., Electrodialysis, a mature technology with a multitude of new applications. Desalination, 264 (2010), 268-288.

82. Stuart P. R., El-Halwagi M. M., Integrated biorefineries: Design, analysis, and optimization, CRC Press, Boca Raton, USA, 2012.

83. Vane L. M., Separation technologies for the recovery and dehydration of alcohols from fermentation broths, Biofuels, Bioproducts and Biorefining, 2 (2008), 553-588. 
1 84. Wang Y., Huang C., Xu T. Which is more competitive for production of organic acids,

2

3

5

6

7

8

9

10 


\section{$1 \quad$ Tables}

2

3 Table 1. Bioethanol dehydration process comparison in terms of key performance indicators

\begin{tabular}{|c|c|c|c|c|}
\hline Key performance indicator & $\begin{array}{l}\text { Classic } \\
\text { process }\end{array}$ & $\begin{array}{c}\text { E-DWC } \\
\text { process }\end{array}$ & $\begin{array}{c}\text { VRC E- } \\
\text { DWC } \\
\text { process }\end{array}$ & $\begin{array}{l}\text { Difference } \\
\text { vs. classic } \\
(\%)\end{array}$ \\
\hline \multicolumn{5}{|l|}{ Equipment cost breakdown (k\$) } \\
\hline - column shells (incl. internals) & 1,103 & 1,111 & 912 & \\
\hline - condensers (heat exchangers) & 1,335 & 1,073 & 71 & \\
\hline - reboilers (heat exchangers) & 885 & 1,442 & 356 & \\
\hline - process-process heat exchangers & 137 & - & 1,503 & \\
\hline - compressor (VRC) & - & - & 1,632 & \\
\hline Total investment costs, TIC (k\$) & 3,462 & 3,626 & 4,477 & +29.3 \\
\hline Total operating costs, TOC $\left(\mathrm{k} \$ \mathrm{yr}^{-1}\right)$ & 5,784 & 5,355 & 4,221 & -27.0 \\
\hline Total annual costs, TAC $\left(\mathrm{k} \$ \mathrm{yr}^{-1}\right)$ & 6,130 & 5,718 & 4,668 & -23.8 \\
\hline $\mathrm{CO}_{2}$ emissions $\left(\mathrm{kg} \mathrm{CO}_{2} \mathrm{t}^{-1}\right.$ product $)$ & 288.94 & 288.31 & $\begin{array}{c}173.04 \\
(112.35)\end{array}$ & $-40.1(-61.1)$ \\
\hline Thermal energy use ( $\mathrm{MJ} \mathrm{kg}^{-1}$ product) & 7.45 & 7.45 & 2.88 & -61.1 \\
\hline Electrical energy use ( $\mathrm{MJ} \mathrm{kg}^{-1}$ product) & $\mathrm{n} / \mathrm{a}$ & $\mathrm{n} / \mathrm{a}$ & 0.50 & $\mathrm{n} / \mathrm{a}$ \\
\hline Equivalent energy requirements $\left(\mathrm{MJ} \mathrm{kg}^{-1}\right)$ & 7.45 & 7.45 & 4.46 & -40.1 \\
\hline
\end{tabular}

$4 \quad *$ Values given in parenthesis are for the case when electricity is generated from renewable sources. 
2 Table 2. Comparison between integrated reactive-absorption vs reactive-distillation processes (at a plant capacity of $1250 \mathrm{~kg} \mathrm{~h}^{-1}$ fatty esters)

\begin{tabular}{|c|c|c|c|c|}
\hline Equipment / Parameter / Units & $\mathbf{R D}$ & HI-RD & $\mathbf{R A}$ & HI-RA \\
\hline Reactive column - reboiler duty (heater), $\mathrm{kJ} \mathrm{s}^{-1}$ & 136 & 136 & $\mathrm{n} / \mathrm{a}$ & $\mathrm{n} / \mathrm{a}$ \\
\hline HEX-1 heat duty (fatty acid heater), $\mathrm{kJ} \mathrm{s}^{-1}$ & 95 & 0 & 108 & 27 \\
\hline HEX-2 heat duty (methanol heater), $\mathrm{kJ} \mathrm{s}^{-1}$ & 8 & 0 & 65 & 0 \\
\hline Reactive column - condenser duty (cooler), $\mathrm{kJ} \mathrm{s}^{-1}$ & -72 & -72 & $\mathrm{n} / \mathrm{a}$ & $\mathrm{n} / \mathrm{a}$ \\
\hline HEX-3 water cooler/decanter, $\mathrm{kJ} \mathrm{s}^{-1}$ & -6 & -6 & -77 & 0 \\
\hline COOLER heat duty (biodiesel cooler), $\mathrm{kJ} \mathrm{s}^{-1}$ & -141 & -38 & -78 & -14 \\
\hline FLASH heat duty (methanol recovery), $\mathrm{kJ} \mathrm{s}^{-1}$ & 0 & 0 & 0 & 0 \\
\hline Compressor power (electricity), $\mathrm{kJ} \mathrm{s}^{-1}$ & 0.6 & 0.6 & 0.6 & 0.6 \\
\hline Reactive column, number of reactive stages & 10 & 10 & 10 & 10 \\
\hline Feed stage number, for acid / alcohol streams & $3 / 10$ & $3 / 10$ & $1 / 15$ & $1 / 15$ \\
\hline Reactive column diameter, $\mathrm{m}$ & 0.4 & 0.4 & 0.4 & 0.4 \\
\hline Reflux ratio (mass ratio $\mathrm{R} / \mathrm{D}$ ), $\mathrm{kg} \mathrm{kg}^{-1}$ & 0.10 & 0.10 & $\mathrm{n} / \mathrm{a}$ & $\mathrm{n} / \mathrm{a}$ \\
\hline Boil-up ratio (mass ratio V/B), $\mathrm{kg} \mathrm{kg}^{-1}$ & 0.12 & 0.12 & $\mathrm{n} / \mathrm{a}$ & $\mathrm{n} / \mathrm{a}$ \\
\hline Productivity, $\mathrm{kg}_{\text {ester }} \mathrm{kg}^{-1}$ catalyst $\mathrm{h}^{-1}$ & 20.4 & 20.4 & 19.2 & 19.2 \\
\hline Energy requirements per ton biodiesel, $\mathrm{MJ} \mathrm{t}^{-1}$ FAME & 688.3 & 391.6 & 498.2 & 77.7 \\
\hline Steam consumption, $\mathrm{kg}$ steam $\mathrm{t}^{-1} \mathrm{FAME}$ & 295 & 168 & 214 & 34 \\
\hline
\end{tabular}


$1 \quad$ Figure captions (auto-updated)

2

3 Figure 1. Analogy between petroleum refinery (left) and biorefinery (right)

4

Figure 2. Estimated energy requirements (as percent of heating value of butanol) and selectivity (defined as $(\mathrm{XBuOH} / \mathrm{XH} 2 \mathrm{O})$ prod / $(\mathrm{XBuOH} / \mathrm{XH} 2 \mathrm{O})$ feed) for the recovery of 2 $\%$ wt 1-butanol from aqueous solution. The numbers $\mathrm{x} / \mathrm{y}{ }^{\circ} \mathrm{C}$ represent the temperature for recovery and regeneration (based on the data from Oudshoorn et al., 2009).

Figure 3. Steam costs for distillation of acetic acid and water as function of the molar fraction of acetic acid in the feed (a reflux ratio of 3 and a steam price of $6 € / G J$ were assumed)

Figure 4. Vapor recompression (VRC) assisted extractive dividing-wall column (E-DWC) for bioethanol concentration and dehydration

Figure 5. Heat integrated reactive distillation (top) and reactive absorption (bottom) processes for biodiesel production

Figure 6. Energy requirements for a conventional two-step process based on FFA pretreatment and trans-esterification (top) versus reactive separation processes (bottom)

Figure 7. Trans-esterification of $\gamma-\bar{\omega} \alpha \lambda \varepsilon \rho \circ \lambda \alpha \chi \tau o v \varepsilon$ with methanol to methyl pentenoates $\left(200{ }^{\circ} \mathrm{C}\right.$, lactone $:$ pTSA $=50: 1$ molar ratio, $\mathrm{MeOH}$ feed rate $=11$ mol molpTSA- $\left.1 \mathrm{~h}-1\right)$

Figure 8. Lower critical solution temperature (LCST) phase diagram for glycol ethers (based on data from Christensen et al., 2005). Squares: water + diethylene glycol 2-methyl-1-butyl ether, circles: water + diethylene glycol n-pentyl ether, triangles: water + triethylene glycol nheptyl ether

Figure 9. Process block diagram of direct liquefaction followed by extraction of the light oil and subsequent recovery of the extraction solvent

Figure 10. Conceptual process for extraction of lipids from microalgae with a secondary amine solvent. After the extraction stage, a CO2-induced phase splitting stage allows recovery of the oil from the solvent, after which the solvent is regenerated by bubbling nitrogen. 


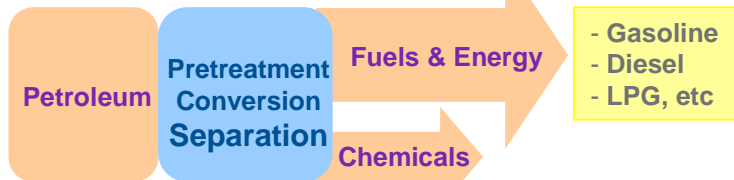

Building blocks to make any chemicals - BTX (benzene, toluene, xylene)

- C1-C3 (methane, ethylene, propylene)

-1,3-butadiene

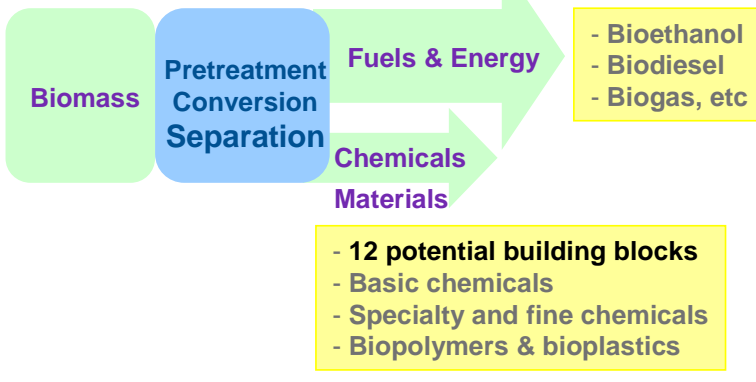

- Ongoing conceptual \& technological developments

- Variable composition of raw materials

- Feedstock relatively heterogeneous

- High oxygen content $(\mathrm{O} / \mathrm{C}$ ratio $>0.4)$

- High water content (energy intensive removal)

- Combined processes: large to smaller molecules

- Separation accounts for $60-80 \%$ of costs

Figure 1. Analogy between petroleum refinery (left) and biorefinery (right)

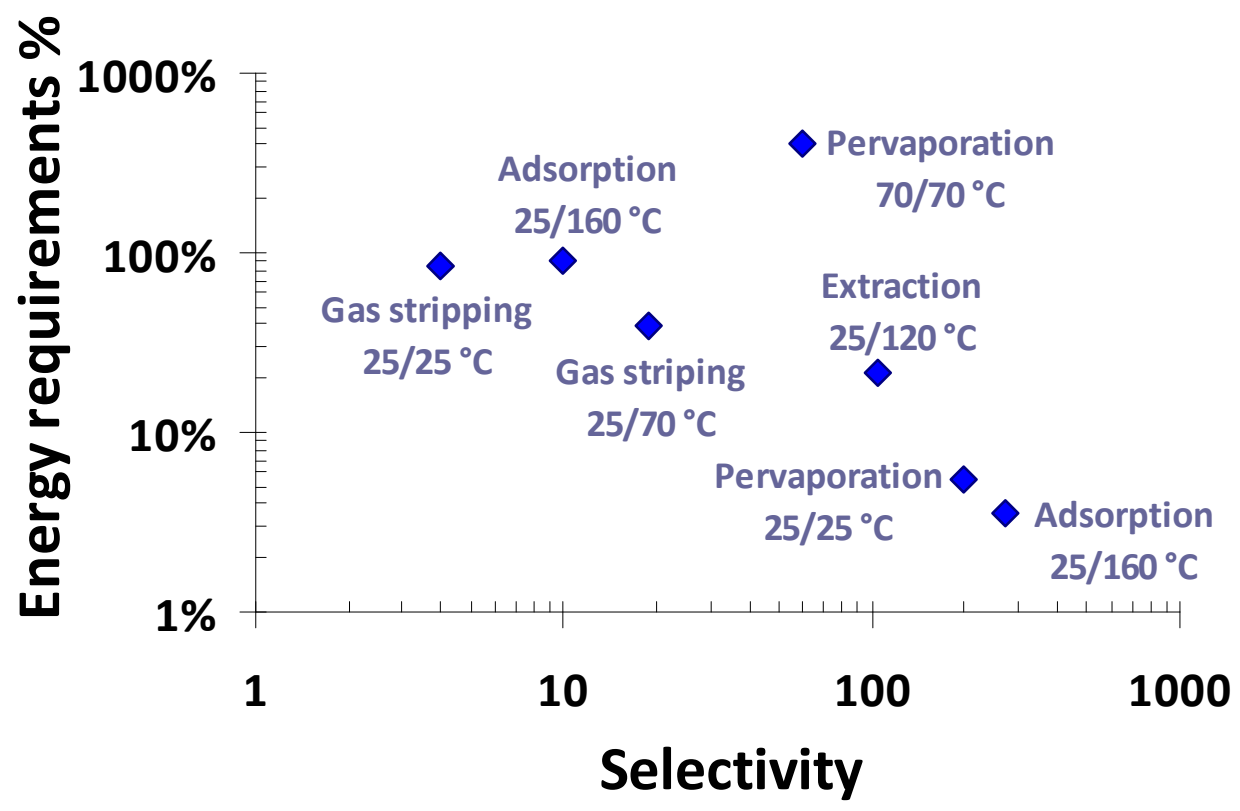

Figure 2. Estimated energy requirements (as percent of heating value of butanol) and selectivity (defined as $\left.\left(\mathrm{X}_{\mathrm{BuOH}} / \mathrm{X}_{\mathrm{H} 2 \mathrm{O}}\right)_{\text {prod }} /\left(\mathrm{X}_{\mathrm{BuOH}} / \mathrm{X}_{\mathrm{H} 2 \mathrm{O}}\right)_{\text {feed }}\right)$ for the recovery of $2 \%$ wt 1 -

11 butanol from aqueous solution. The numbers $\mathrm{x} / \mathrm{y}{ }^{\circ} \mathrm{C}$ represent the temperature for recovery and regeneration (based on the data from Oudshoorn et al., 2009). 


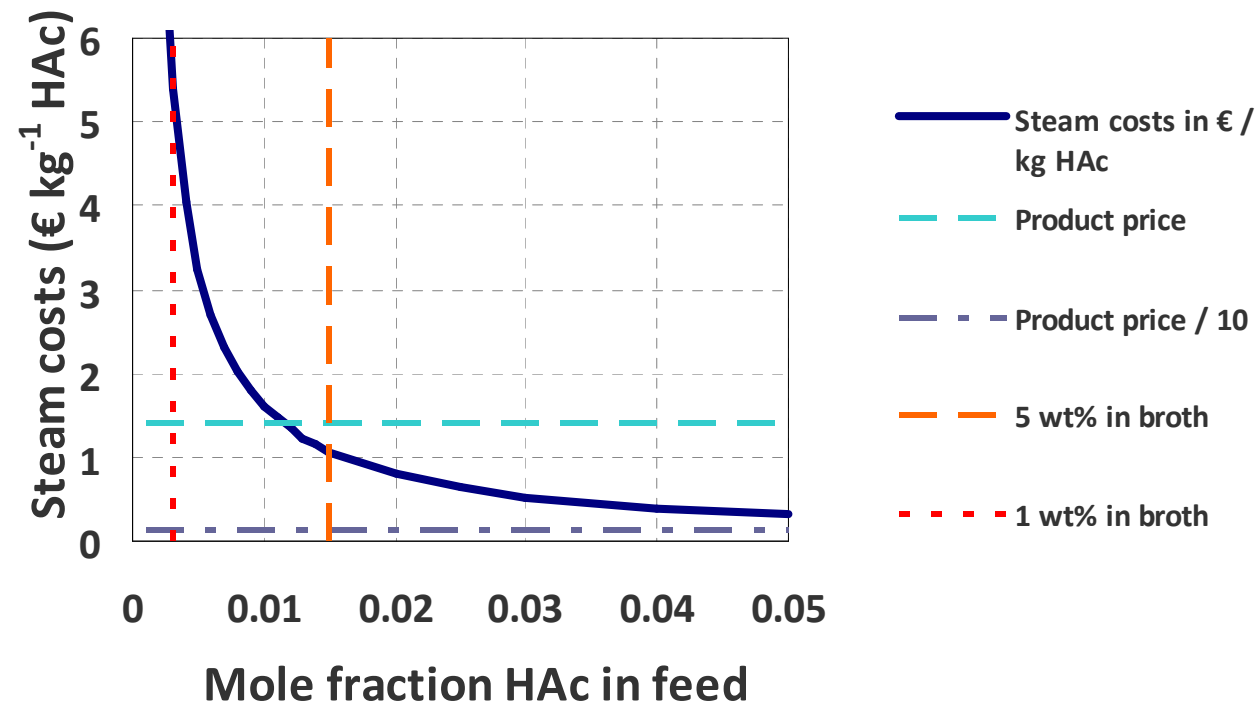

2 Figure 3. Steam costs for distillation of acetic acid and water as function of the molar fraction

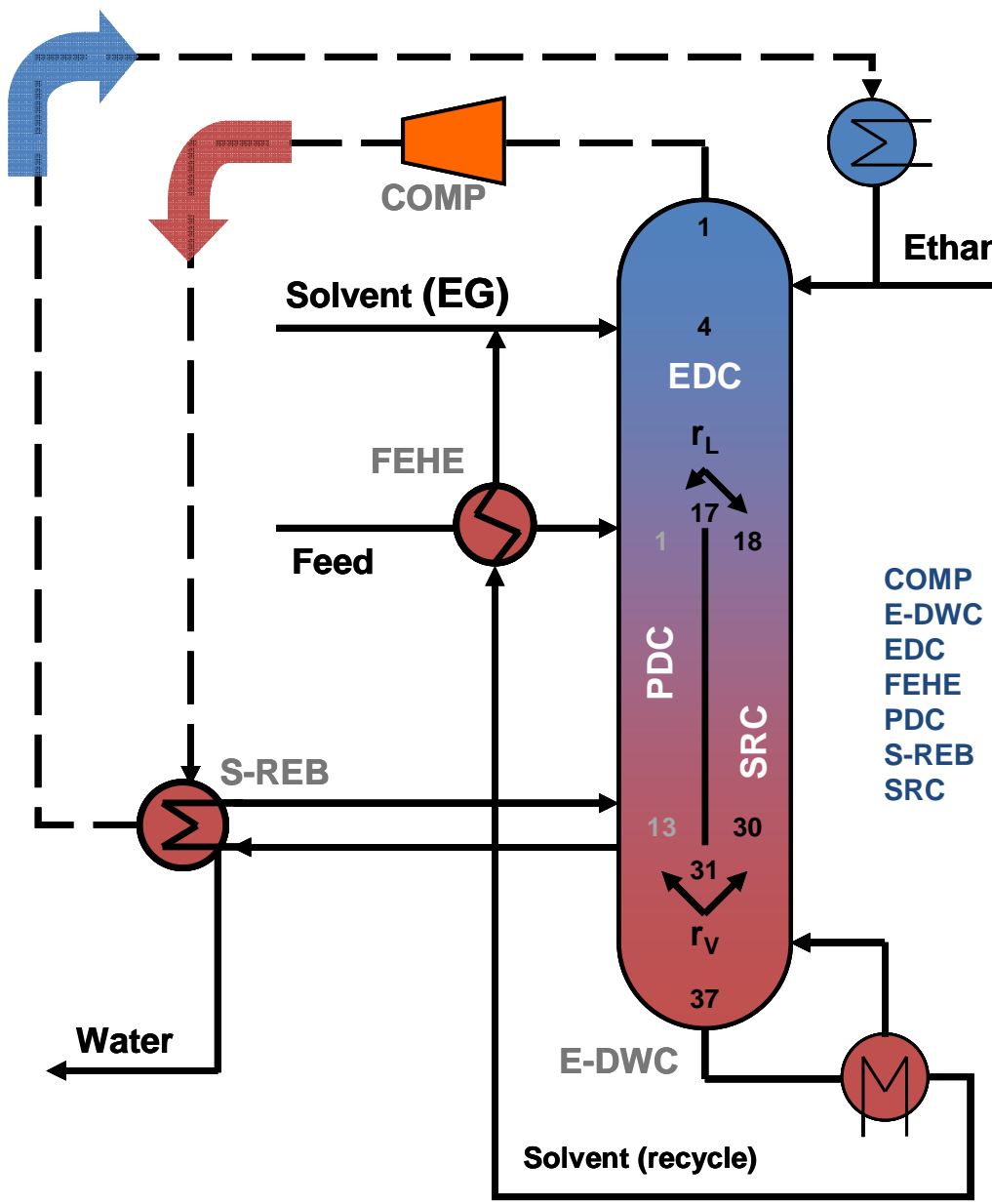

6 Figure 4. Vapor recompression (VRC) assisted extractive dividing-wall column (E-DWC) for bioethanol concentration and dehydration 

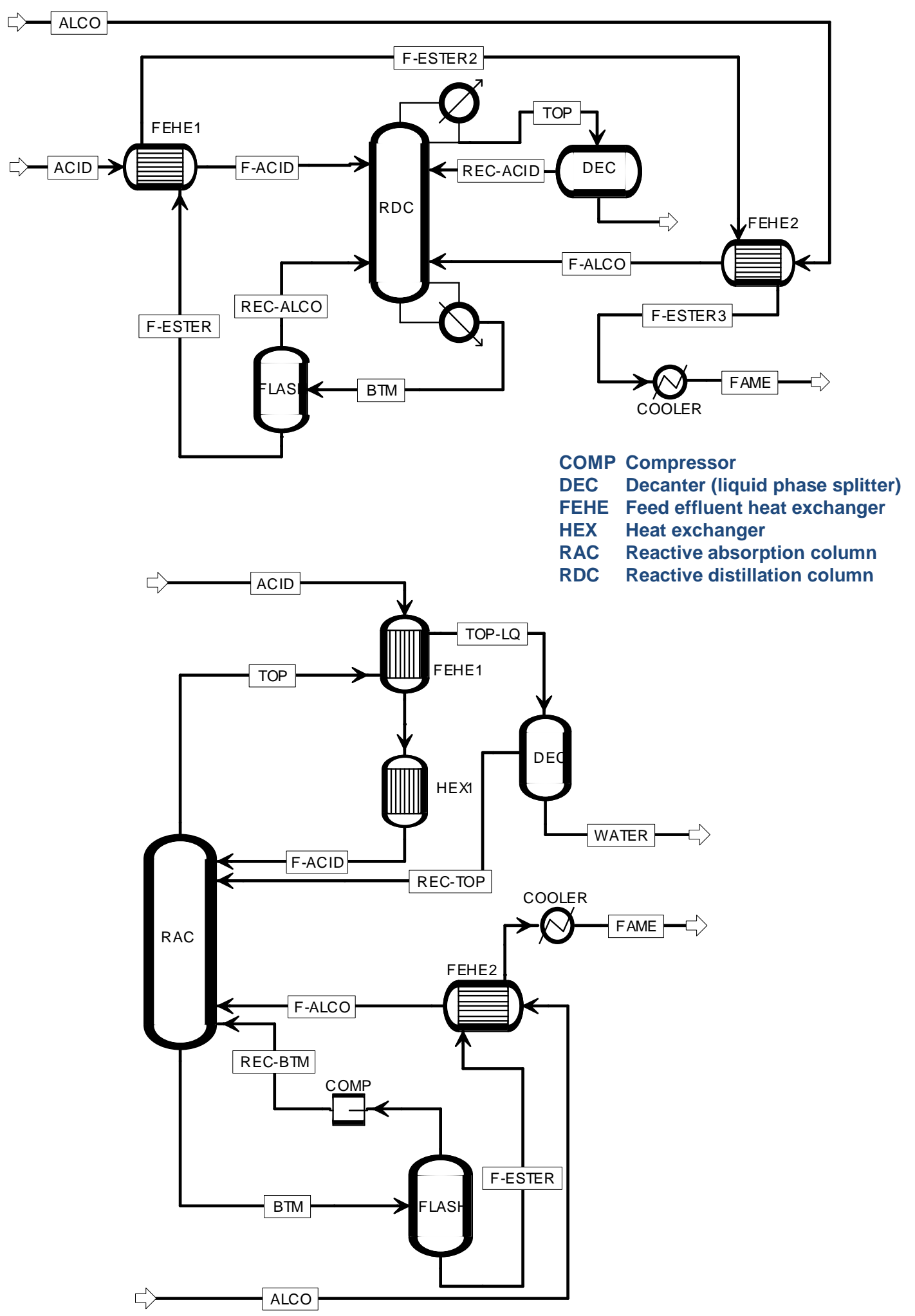

5 Figure 5. Heat integrated reactive distillation (top) and reactive absorption (bottom) processes 

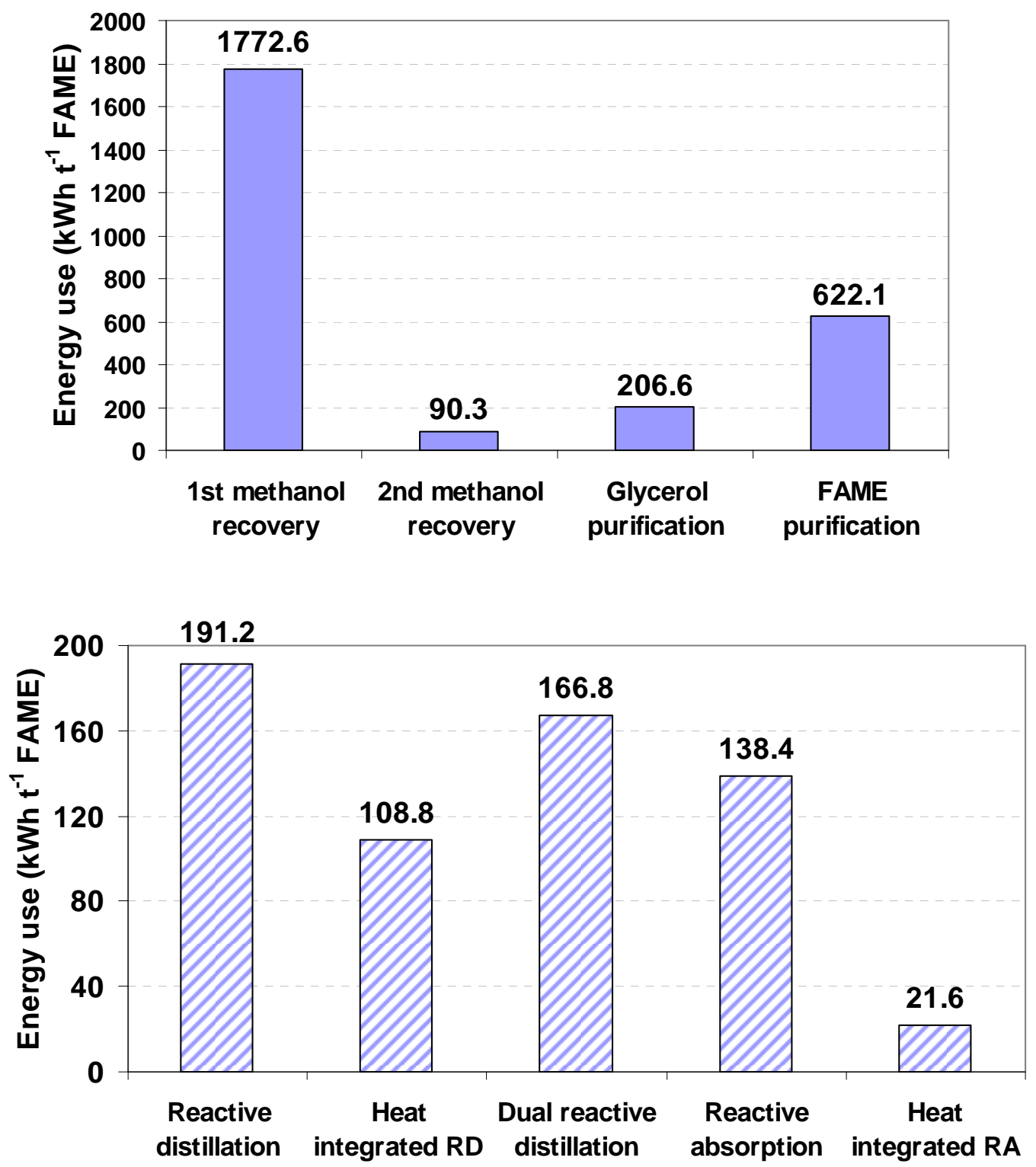
<smiles></smiles>

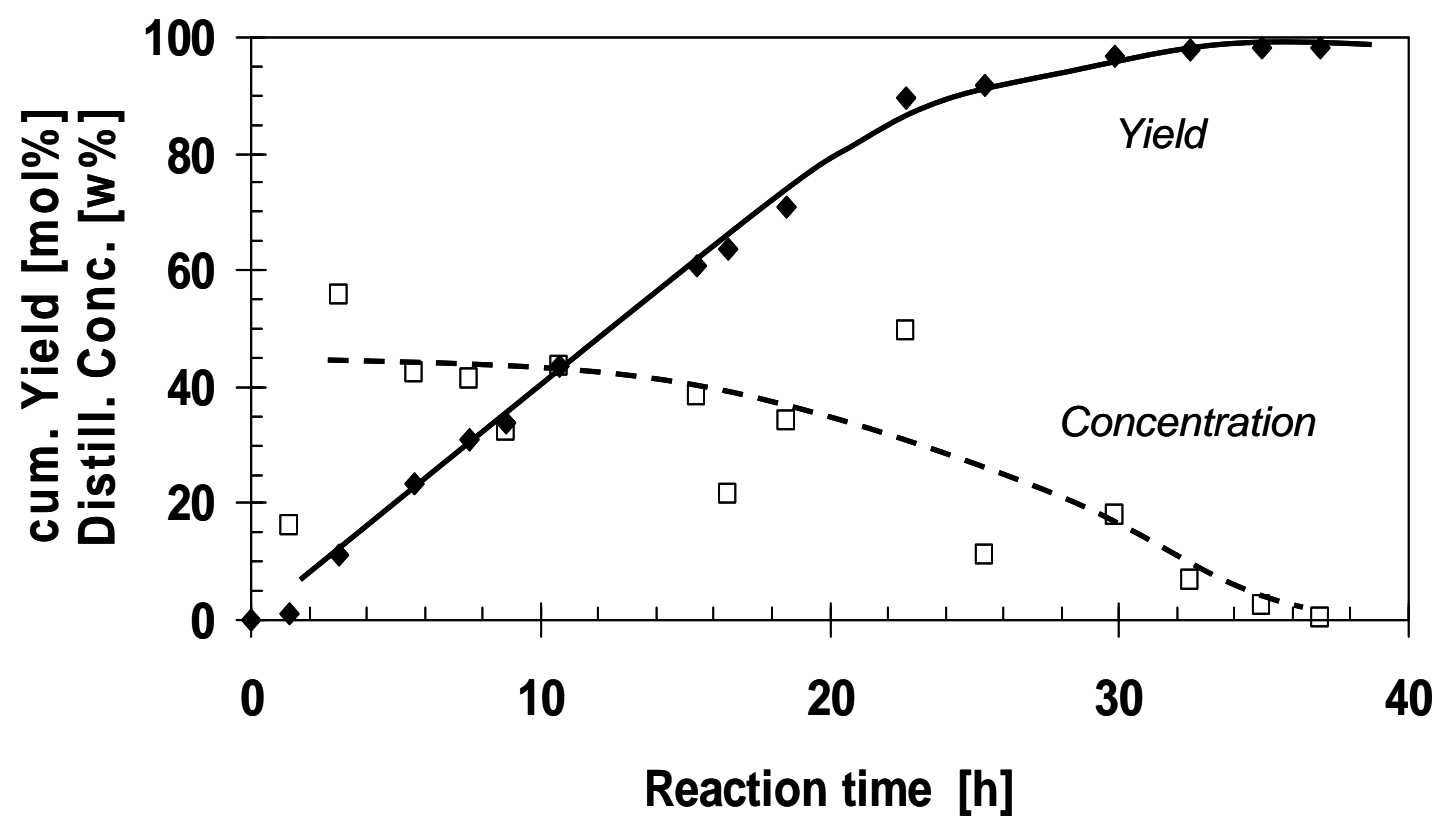

Figure 7. Trans-esterification of $\gamma$-valerolactone with methanol to methyl pentenoates (200

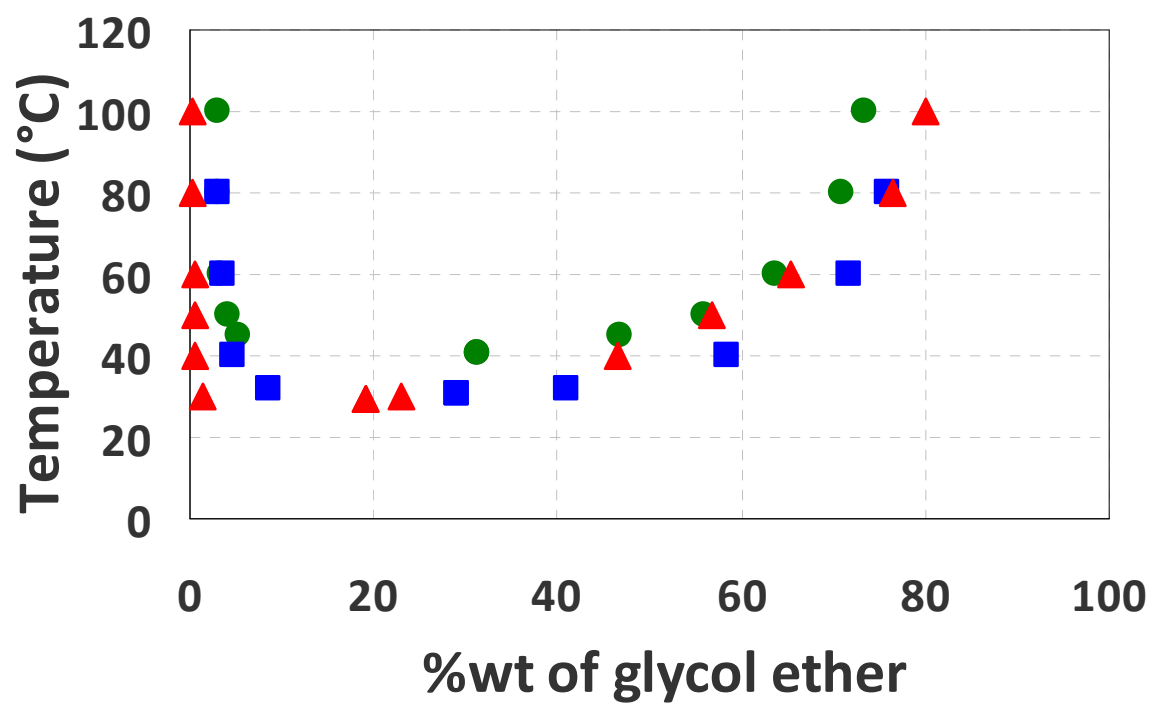

Figure 8. Lower critical solution temperature (LCST) phase diagram for glycol ethers (based on data from Christensen et al., 2005). Squares: water + diethylene glycol 2-methyl-1-butyl ether, circles: water + diethylene glycol n-pentyl ether, triangles: water + triethylene glycol n- 
3

4

5

6

7

8

9

10

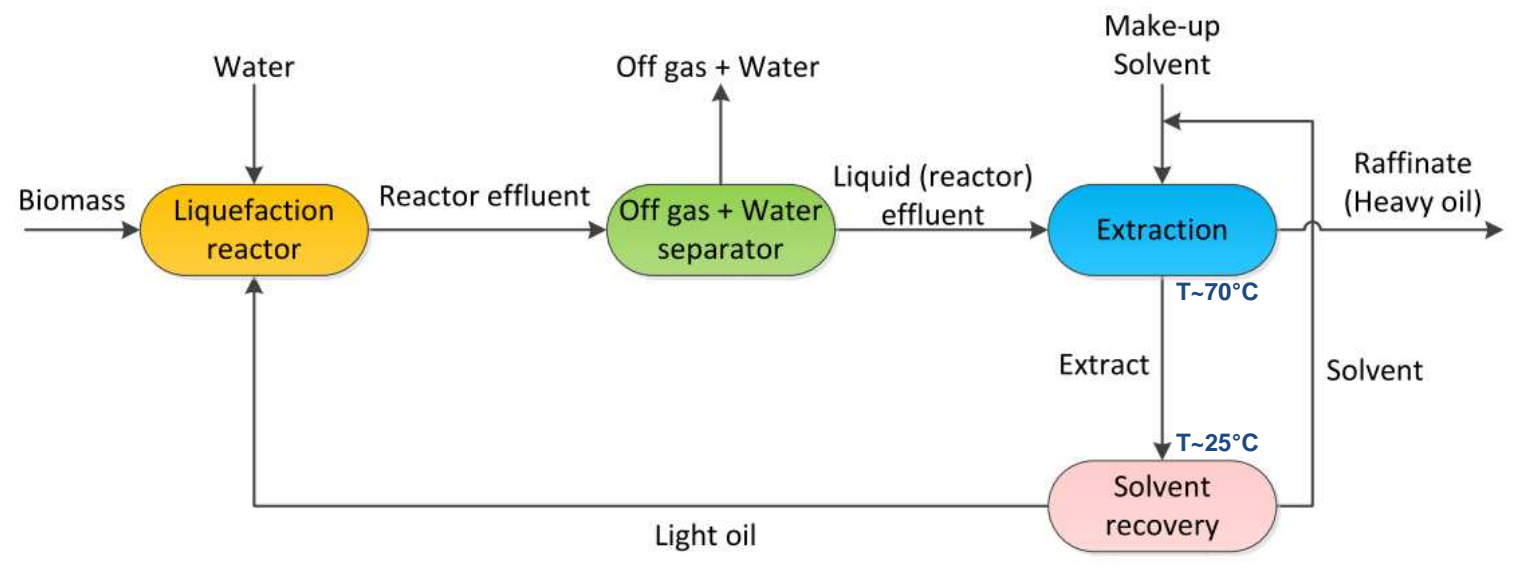

Figure 9. Process block diagram of direct liquefaction followed by extraction of the light oil and subsequent recovery of the extraction solvent

(1)

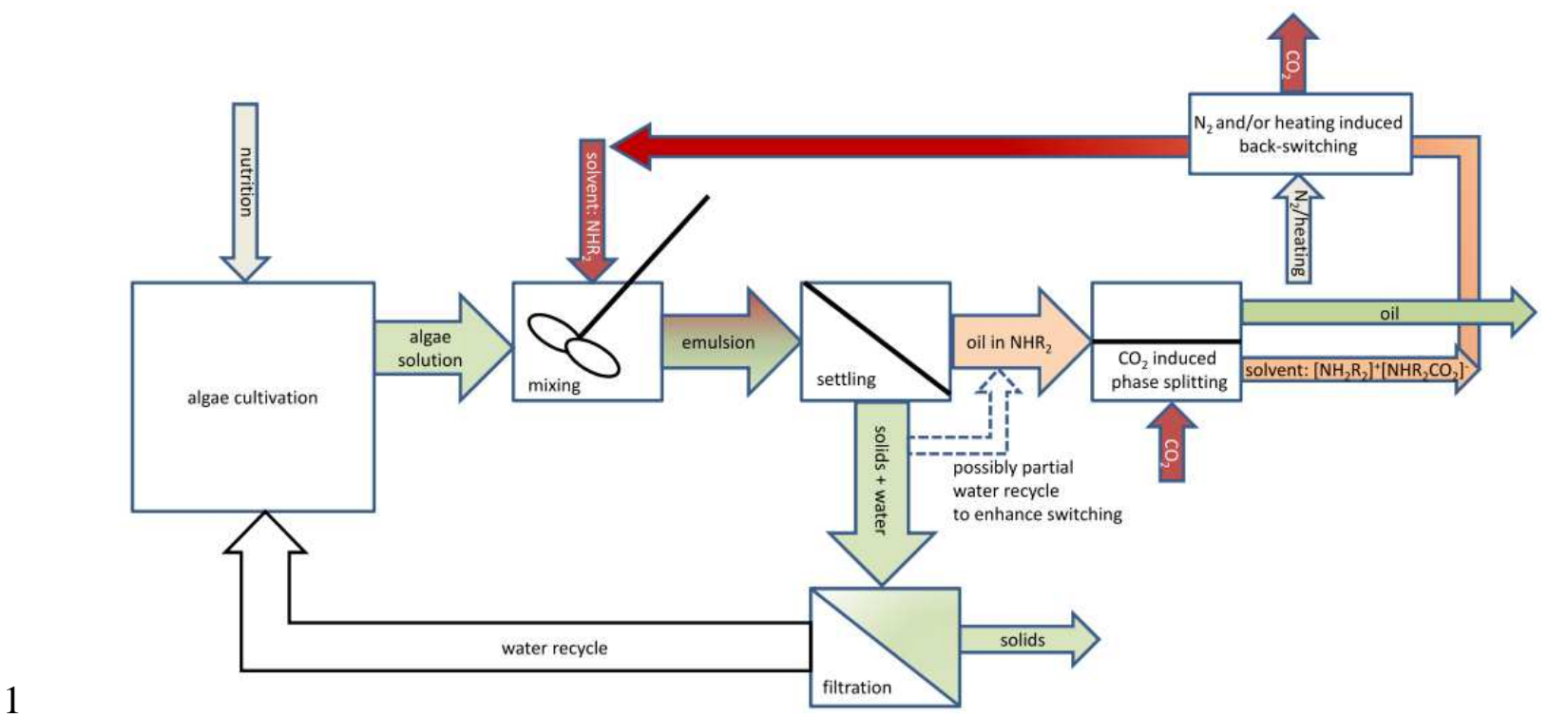

2 Figure 10. Conceptual process for extraction of lipids from microalgae with a secondary 3 amine solvent. After the extraction stage, $\mathrm{a} \mathrm{CO}_{2}$-induced phase splitting stage allows recovery 4 of the oil from the solvent, after which the solvent is regenerated by bubbling nitrogen. 